Journal of Environmental Studies [JES] 2010. 4: 35- 57

Article

معيقات التربية الديمقر اطية وعلاقتها ببعض المتغيرات الديموجر افية كما تــــركها عينة من طلاب

الجحامعات الأردنية

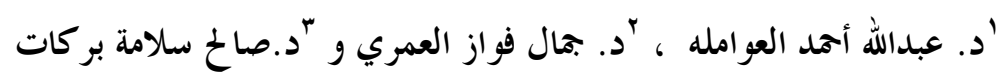
'أستاذ مساعد اصول التربية بجامعة البلقاء التطبيقية "أستاذ مساعد ادارة تربوية بجامعة البلقاء النطبيقية "أستاذ مساعد اصول التربية بجامعة البلقاء النطبيقية

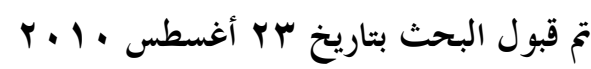

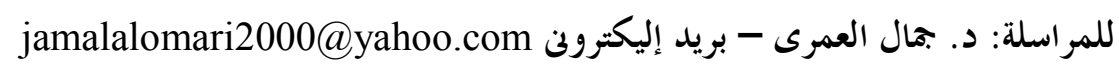

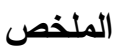

هدفت الدراسة الحالية إلي الكثف عن معيقات التربية الديمقر اطية السياسية ، و الاجتماعية ، و الاقتصادية ، و التربوية ، و الثقافية كما تدركها عينة من طلاب الجامعات الأردنية ، و التعرف علي علاقة هذه المعيقات ببعض التهن المتغيرات الديموجر افية قيد البحث في هذه الدراسة (الجنس، المسنوى الدراسي، مكان الإقامة ، العضوية في إحدى الجمعيات أو أولات

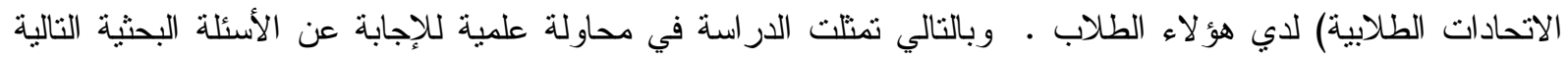

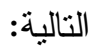

ا ـ ما معيقات التربية الديمقر اطية السياسية ، و الاجتماعية ، و الاقتصادية ، و التربوية ، و الثقافية كما تدركها عينة من

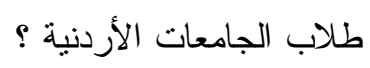

r. هل نوجد فروق ذات دلالة إحصائية بين منوسطات درجات طلاب العينة في معيقات التربية الديمقراطية تبعاً

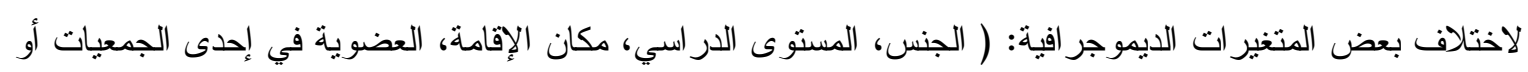

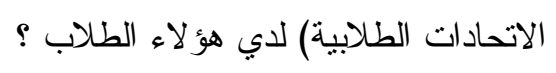

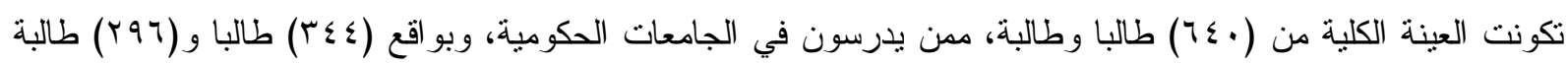
و كثفت الدراسة عن النتائج الثالية :

1. و وجود معيقات في التربية الديمقر اطية في مجالات الدراسة كافة ، وكان أكثر ها في المعيقات الثقافية.

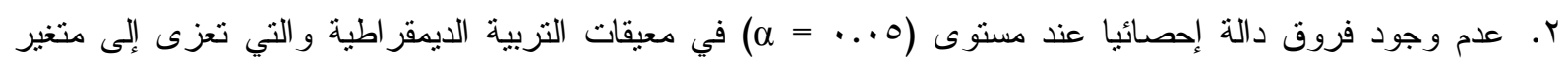
الجنس لكل من الذكور و الإناث.

r. وجود فروق ذات دلالة إحصائيا عند مسنوى (0... = م) بين منوسطات درجات أفراد العينة في المعيقات السياسية

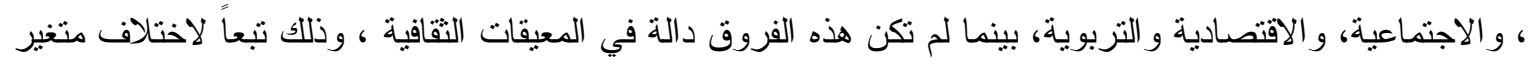

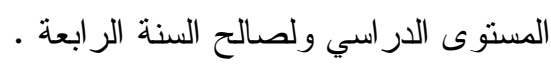

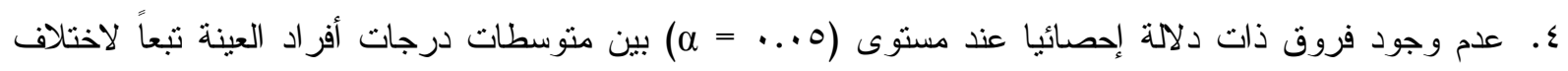

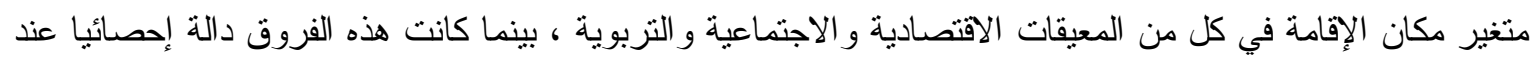
مسنوى (0. . = م) في معيقات التربية الديمقر اطية السياسية و الثقافية وكانت لصالح سكان المخيمات. 
ه. وجود فروق ذات دلالة إحصائيا عند مستوى (0...

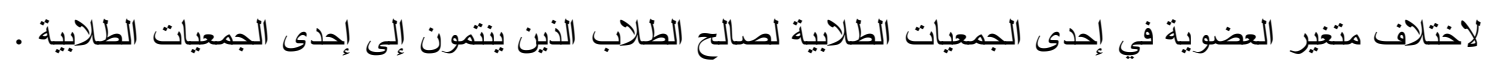

الكلمات المفتاحية: الديموقر اطية، التعليم، المعيقات و طلاب الجامعة الجية

المواطن أصبح حرا في وطنه ولديه جميع الحقوق المدنية ، وعلى الرغم

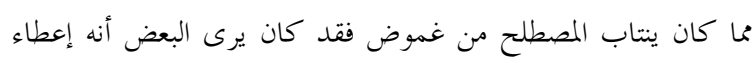

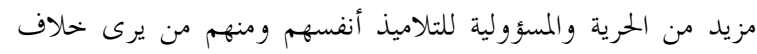

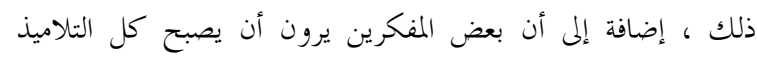

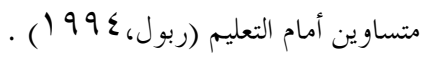

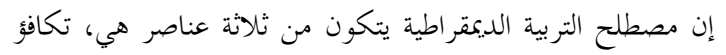

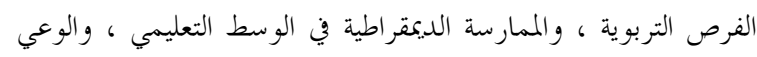

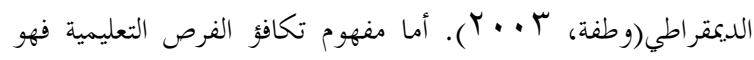

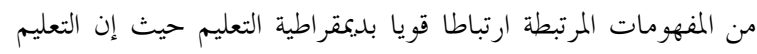

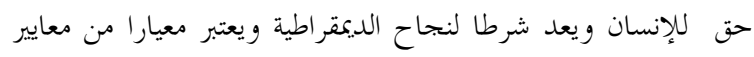

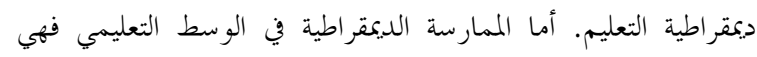

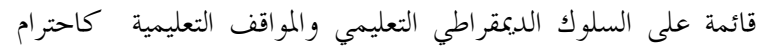

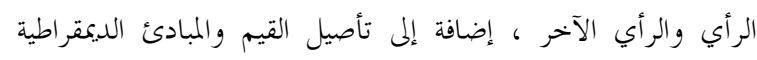

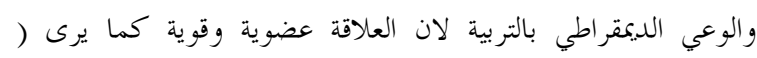

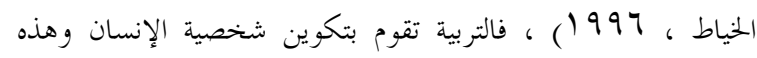

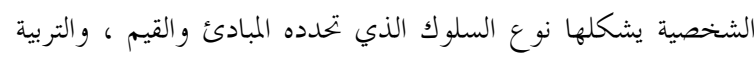

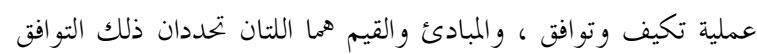
والتكيف، والتربية أيضا تعمل على توفير الأمان للإنسان ، والمبادئ

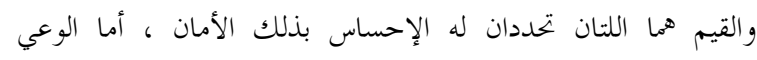

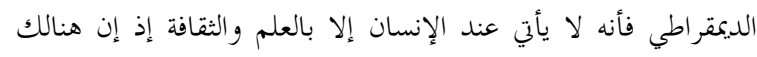

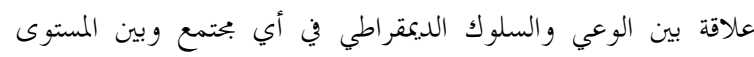

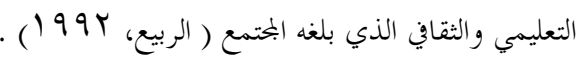

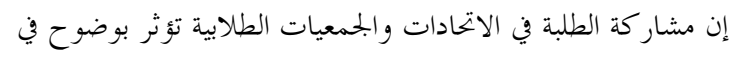
العملية التربوية الديمقراطية ، ولا يخفى على العاملين في البحال التربوي

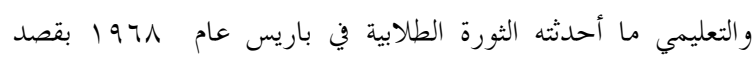

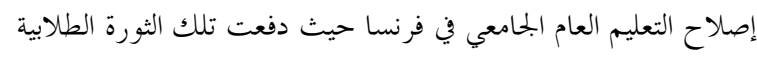

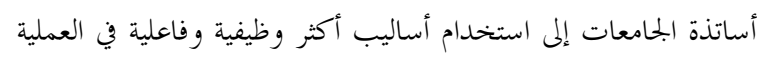

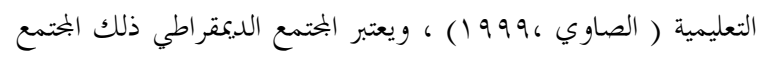

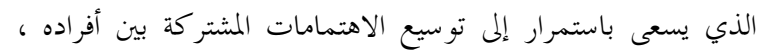

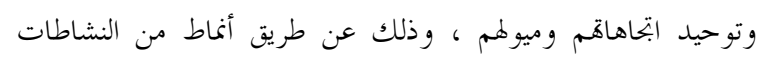
المشروعة وعن طريق التربية ( التل وآخرون، بهو و 19 ) .

\section{مقـــمستة}

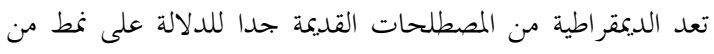
أنماط الحكم حيث يعد الإغريق أول من استنبط فكرة الديمقراطية

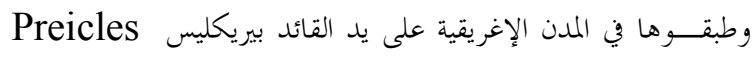

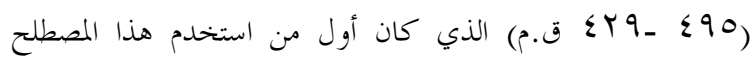

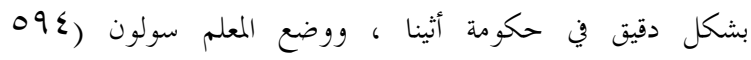

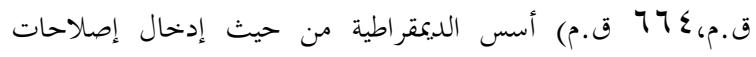

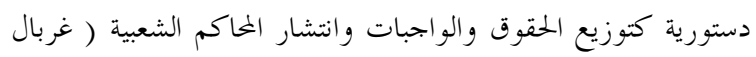
.$(199.6$ وفي أوائل القرن السادس قبل الميلاد استخدمها الأنباط، حيث كان

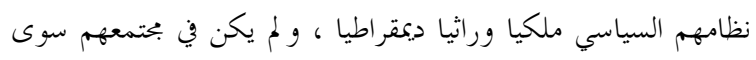

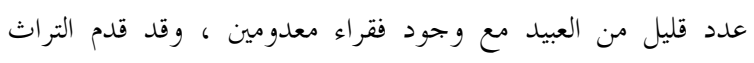

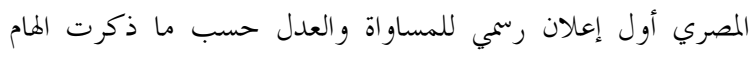

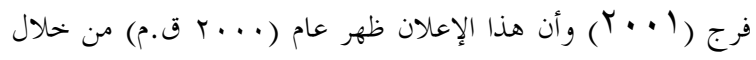

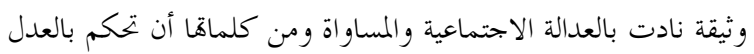
، لان التحيز يعد طغيانا. وفي الإسلام جاءت مضامين عديدة للديمقراطية كالحرية والعدالة

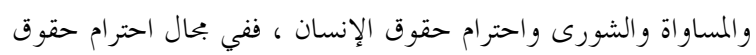

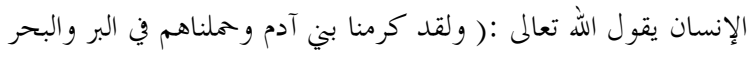

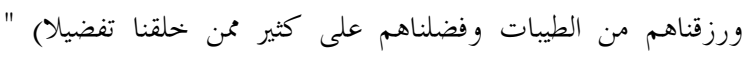

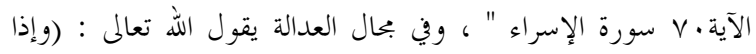

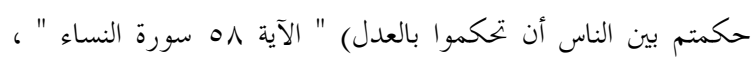

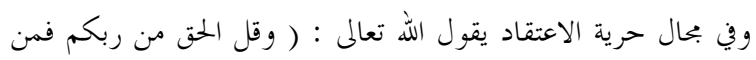

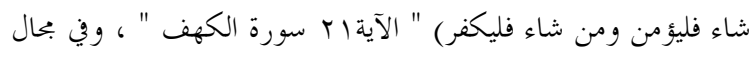

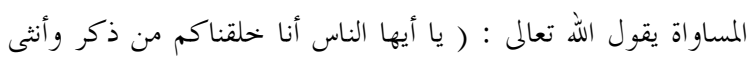

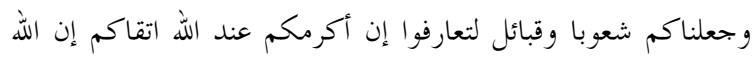

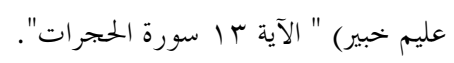

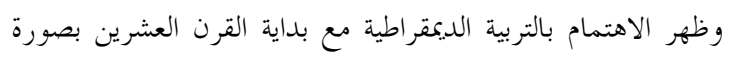

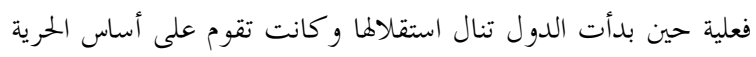

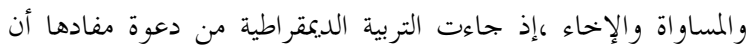


إتباع الطرق السلمية الإرادية لحل التزاعات الطائفية والعرقية والإقليمية

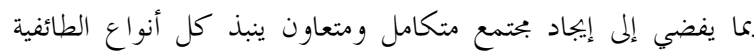
والإقليمية على أساس أن كل مواطن أردني وكل مواطنة أردنية يتتمون

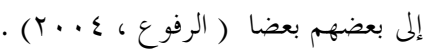

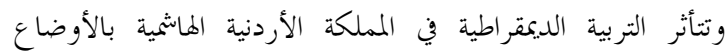

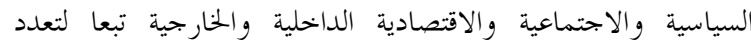
بجالاقا واختلاف وجهات النظر حول المفهومة نفسها ومالاعها وأهدافها ، فهنالك معيقات داخلية تتعلق بالبيئة التشريعية حاليا وعدم

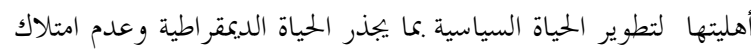

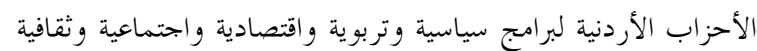

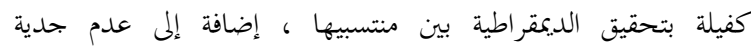

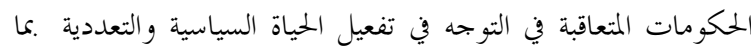

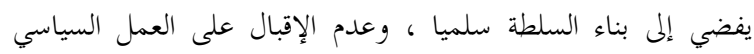

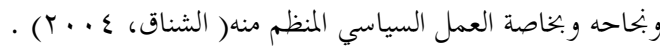
ويعتبر ضعف مستوى الثقافة السياسية للمجتمع عموما وللطلبة خصوصا من معيقات التربية الديمقراطية ، وهي نتيجة حتمية لوجود

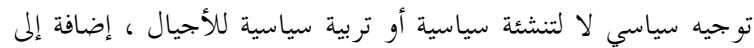

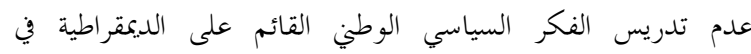

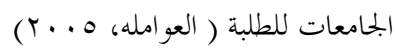
إن تقييد حرية الرأي والتعبير وعدم ضماها وصوها ووجودا ولهو التمييز

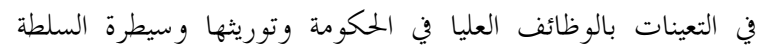
التنفيذية على جهود التنمية ، إضافة إلى ضعف المشاركة السياسية وعدم الإقبال على العمل السياسي بسب انشغال الناس بلقمة العيش وتعدد الولاءات والانتماءات وطغيان الروح الإقليمية والعشائرية

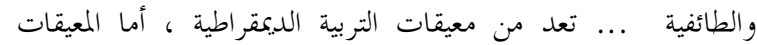

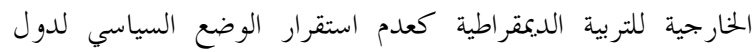

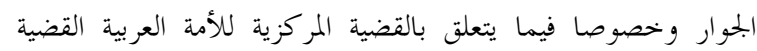

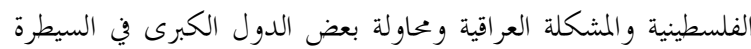
على الاقتصاد والتدخل المباشر وغير المباشر في بعض الشؤون الداخلية

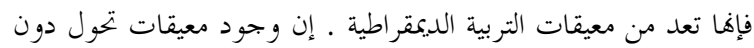

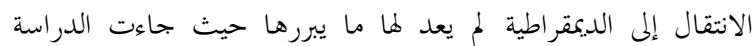

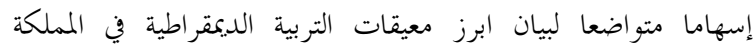

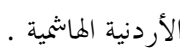

أما الجمامعة فتعتبر بيئة تربوية اجتماعية صاهره تعمل على إحداث التفاعل والتواصل بين الطلبة والأساتذة بحيث بتعل الطالب يتمثل القيم

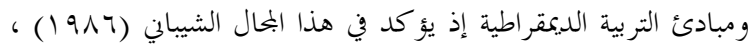

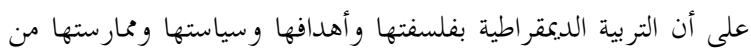
خلال مفاهيمها وأساليبها وإدارتحا تعتبر من غير شك الوسيلة الأكثر فاعلية في تحقيق الهدف ولا يمكن أن تتحقق ديمقراطية حسنة إلا من خلال نظام تعليمي ديمقراطي بجميع عناصره ومكوناته. و تعد الحرية العامة أسسا مهما من أسس الديمقراطية لأها ترتبط

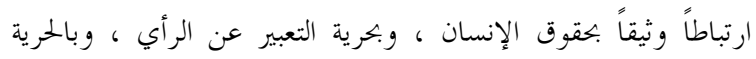

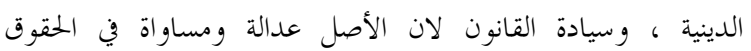
والواجبات ، وتتقيق العدالة الاجتماعية بمعنى عدم شعور الإنسان بالظلم ، واحترام الرأي الآخر يعد من مقومات العمات العمل الديمقراطي

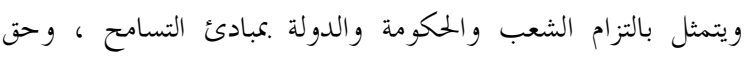

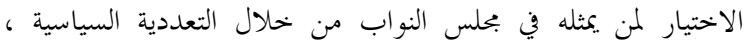

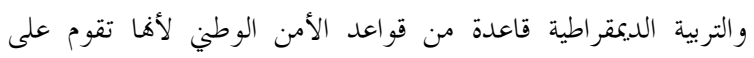

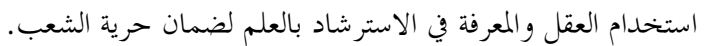
وتختلف أهداف التربية الديمقراطية من دولة إلى أخرى ومن بحتمع إلى آخر ، حيث تتأثر بالظروف الداخلية والخارجية للدولة ، وتعتبر

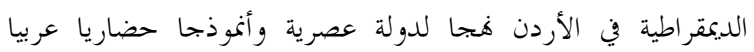
وإسلاميا ، ويرى الرشدان (r . . r) أن أهداف التربية الديمقراطية في الأردن يمكن أن تتلخص .ما يلي:-

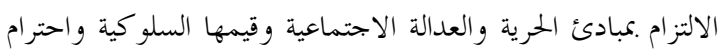
حقوق الإنسان في جميع الظروف في كل مكان وزمان ، واحترام دستور الدولة والالتزام بقوانينها وأنظمتها وتعليماها ، والتحرر من بعن

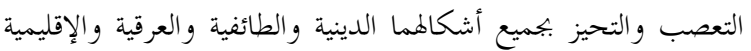

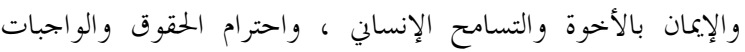

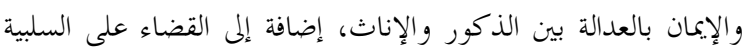

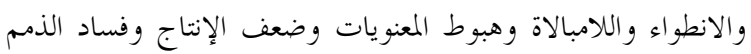

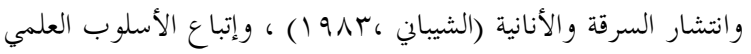

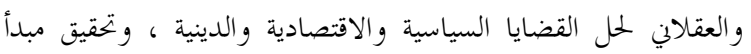
تكافؤ الفرص التعليمية بين جميع المواطنين ، وإعداد الشباب إعداد سليما ليكونوا قادرين على مسايرة متطلبات العصر وتطوراته في

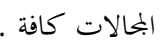
كذلك قدف التربية الديمقراطية إلى تعزيز الهوية الوطنية العربية

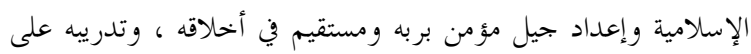



التوجه نخو الديمقراطية التي أصبحت مطلب جميع أنحاء العالم

$$
\text { وحقا من حقوق الإنسان. }
$$

ثانياً: الأهمية التطبيقية حيث ما ما يمكن أن تسهم فيه هذه الدراسة من فائدة عملية في في هذا البحال ان معرفة اندية معيقات التربية الديمقراطية

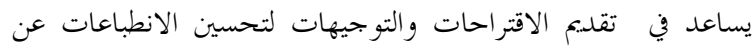
التربية الديمقر اطية.

اقتصرت الدراسة على عينة من طلاب الجامعات الأردنية الحكومية

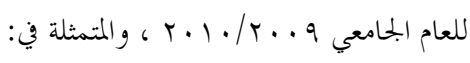

الجامعة الهاشمية ، جامعة مؤتة ،جامعة البلقاء التطبيقية ،جامعة العلوم

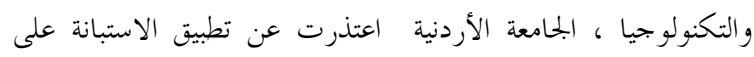
طلبتها .

\section{متغير ات الدراسة}

المتغير ات الديموجر افية: ا. الجنس: ( ذكر / أنثى ) .

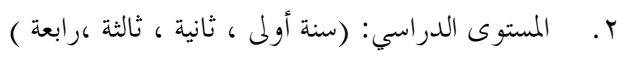
ץ. ب. ب- مكان الإقامة: ( مدينة ، قرية ، بادية: ، مخيم ).

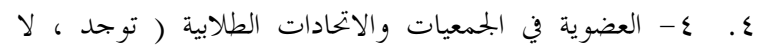

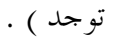

* المتغير الرئيس : معيقات التربية الديمقراطية كما تدركها عينة من

$$
\text { طلاب الجامعات الأردنية. }
$$

الار اسـات السابقة

اطلع الباحثون على العديد من الدراسات السابقة وقد تم الافادة

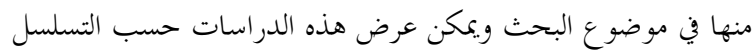

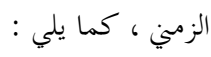

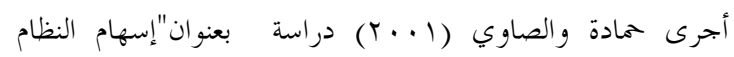
التعليمي في إصلاح المسيرة الديمقراطية في الكويت: دراسة ميدانية ، هدفت الدراسة إلى استطلاع آراء المربين العاملين في مؤسسات التعليم

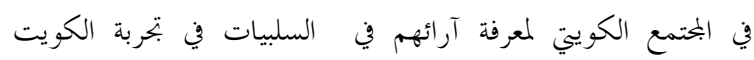

الحيوي . إن وجود قصور في البيئة التربوية والتعليمية في الجامعات لئية على التربية والتنشئة السياسية القائمة على السلوك الديمقراطي وغرس الفضائل في نفوس الطلبة يشكل مشكلة للنظام الديمقراطي ، و وفي ضوء ذلك تحددت مشكلة الدراسة في الإجابة عن السؤ الين التاليين: 1. ما معيقات التربية الديمقراطية السياسية، والاجتماعية،

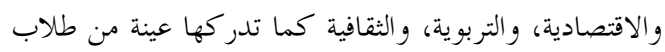

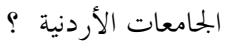

r. هل توجد فروق ذات دلالة إحصائية بين متوسطات درجات

$$
\text { طلاب العينة في معيقات التربية ؟ }
$$

الديمقراطية تبعاً لاختلاف بعض بلمين لمينغيرات الديموجرافية : ( الجنس،

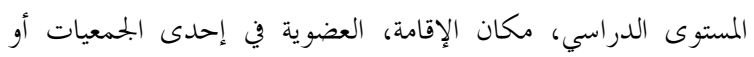
الاتحادات الطلابية) لدي هؤلاء الطلاب ؟ .

\section{أهداف الار اسة}

هدفت الدراسة إلى ما يلي :

1. التعرف علي معيقات التربية الديمقراطية السياسية والاجتماعية

والاقتصادية والتربوية والثقافية كما تدركها عينة من طلاب لمبن

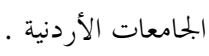

r. التعرف علي طبيعة العلاقة بين متغيرات (الجنس، المستوى

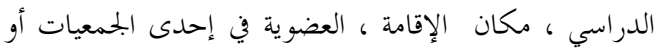

الاتحادات الطلابية) ومعيقات الديمقراطية كما يدر كها هؤلاء

الطلاب.

\section{أهمية الدر اسة}

تنبع أهمية الدراسة من أهميتين هما: أولاً : الأهمية النظرية التي تتضح من:

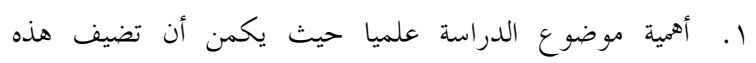

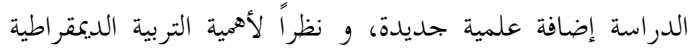

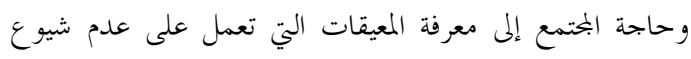

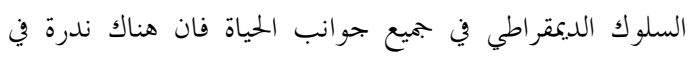


توصلت الدراسة إلى وجود فروق ذات دلالة إحصائية عند مستوى

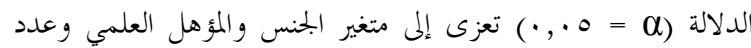

سنوات الخبرة والإقليم والتخصص ونوع الدراسة.

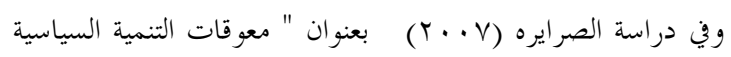
في الأردن "هدفت إلى الكشف عن طبيعة المعوقات التي تلعب دورا

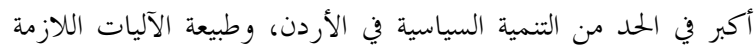

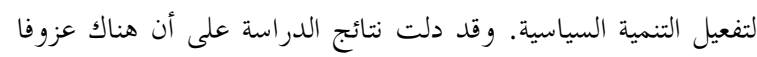
شبه مطلق عن الانتماء للأحزاب السياسية، بسبب توغل الأجهزة

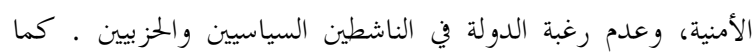
أكدت النتائج على أن مشاركة المواطنين في الانتخابات البرانمانية غالبا

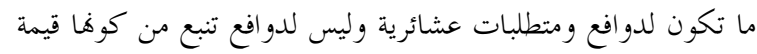

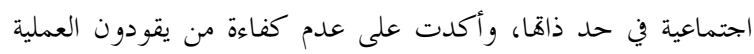
السياسية، وتدلي معرفة المواطنين بشعارات التنمية السياسية من الناحية السلو كية و التطبيقية في الحياة العملية .

الار اسات الأجنبية

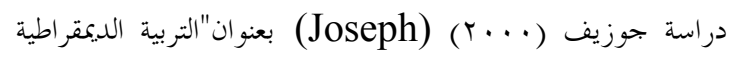

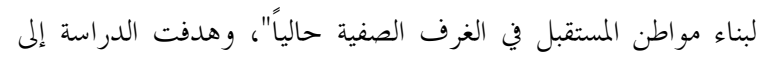

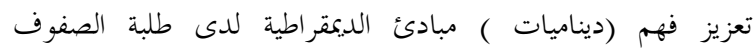

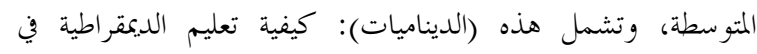

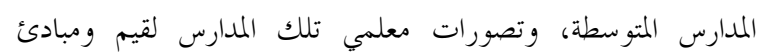
الديمقراطية، وكيف يعمل طلبة تلك المدارس ضمن هذه التصورات. وأظهرت النتائج حاجة تلك المدارس لنموذج ديمقر اطي مثالي في غرفة الصف لإعداد مواطن المستقبل الديمقراطي.

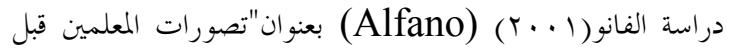

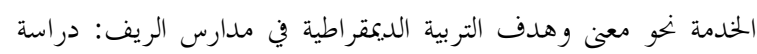
حالة"، وأجريت في أمريكا، وهدفت هذه وهدئ الدراسة إلى تطوير آلية

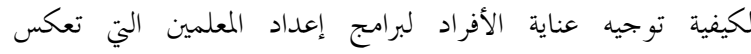
التجديدات التربوية العالمية، وكيفية تشجيعهم للحصول على مؤهل علمي في إطار الحدمة المدنية لإدراك معاني وأهداف التربية الديمقراطية. واستخدم الباحث في هذه الدراسة منهج البحث النوعي من خلال

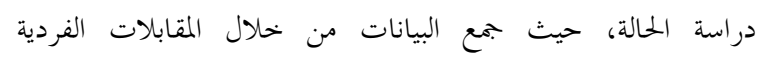
والمقابلات الجماعية المركزة لمحموعة من الأفراد الذين التحقوا ببرامج

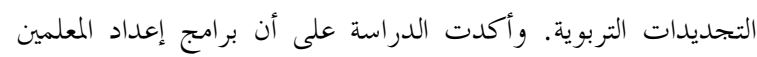

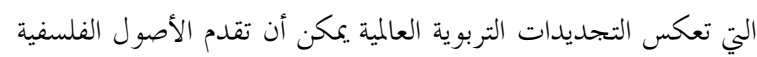

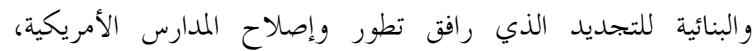

الديمقراطية، وآرائهم في الأثر الذي يمكن أن تحدثه المناهج الدراسية والعلم والأنشطة الطلابية في ترسيخ مبادئ الديمقراطية لدى الطلبة .

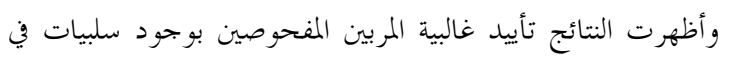

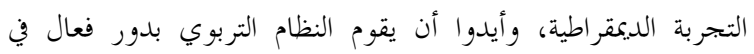
إصلاح تلك التجربة الديمقر اطية ومعالجة سلبياتا. وأوصى الباحثان بضرورة التأكيد على ترسيخ مبدأ المشاركة

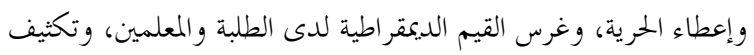

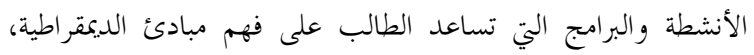
وتعميق القيم الديمقراطية في مناهج المرحلتين المتوسطة والثانوية في المدارس.

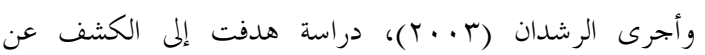
المبادئ و القيم الديمقراطية في فلسفة التربية وأهدافها في الأردن، و وكانت

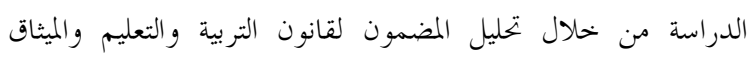
الوطني الأردني، وتوصلت الدراسة إلى أن قانون التربية والتعليم

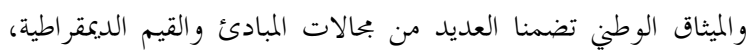
ووضوح انعكاساها على واقع العملية التربوية، كما توصلت إلى إلى التوافق بين فلسفة التربية والميثاق الوطني في تأكيدهما على مبادئ

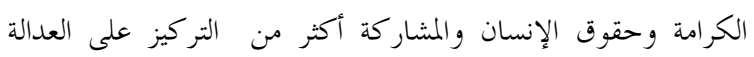
والمساواة والتسامح، كما جاء التأكيد على القيم العلمية والمعرفية التهنية والاقتصادية أكثر من القيم الخلقية والإنسانية والبيئية والصحية.

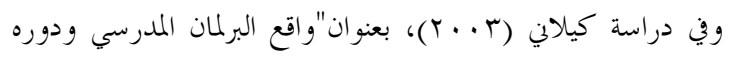

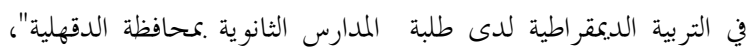
حيث تنوعت أدوات الدراسة فيها و كانت تتكون من استبانة ومن

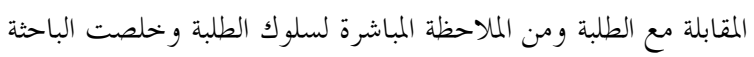

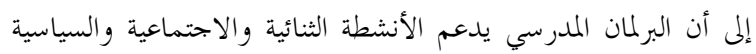

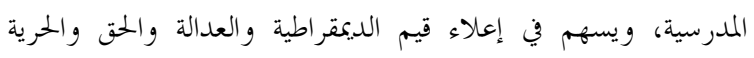

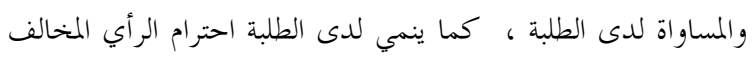
والالتزام بالتقاليد و السلوك الديمقراطي في المشار كة.

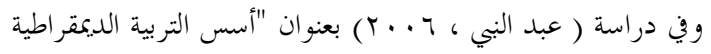

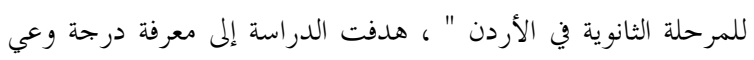
معلمي المرحلة الثانوية بالممارسات التي تعبر عن أسس التردية التردية الديمقراطية ، حيث توصلت الدراسة إلى أن وعي المعلمين بأسس التربية

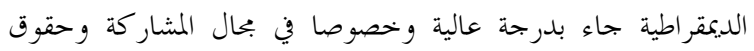
الإنسان أما في بحال العدالة فجاء وعيهم متدنيا ، وفي بحال الحرية كان

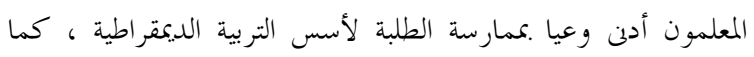




\section{المنهج و الإجراءات}

أولاً منهج الدراسة : نظراً لطبيعة هذه الدراسة من حيث نوعية

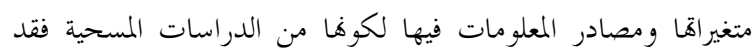

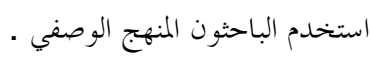
ثانيا مجتمع الدراسة وعينتها: تكون بحتمع الدراسة من طلبة الجامعات

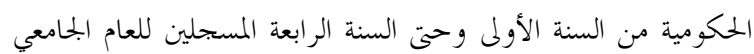

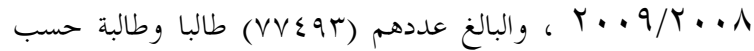
إحصائية وزارة التعليم العلاي ، كما قام الباحثون بتطبيق أداة الدراسة

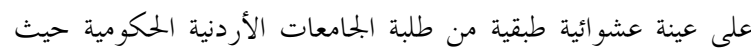

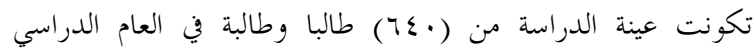

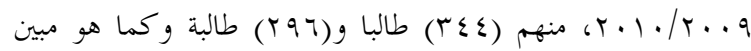

في الجحول رقم (1)

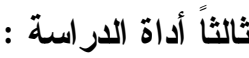

قام الباحثون بتطوير استبانه تكونت من (1^) فقرة تم إعدادها من خلال الرجوع إلى الأدب التربوي والدراسات السابقة، وبعض أعضاء

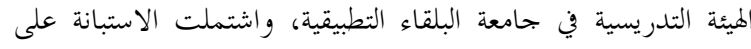

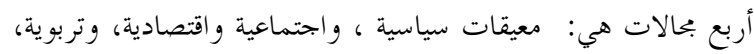
وثقافية.

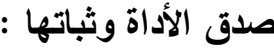

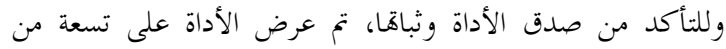
الحكمين المختصين في بجال التربية والقياس والتقويم والعلوم السياسية

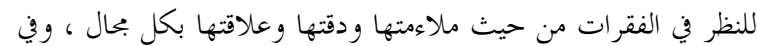
ضوء ملاحظات المحكمين تم حذف بعض الفقرات وتعديل فقرات أخرى ، هذا وقد بلغ عدد الفقرات بصورةا النهائية (مه) فقرة. كذلك تم التحقق من ثبات الاستبانة من خلال تطبيقها على ثلاثين طالبا وطالبة من بحتمع الدراسة وخارج العينة الأساسية مرتين بفارق

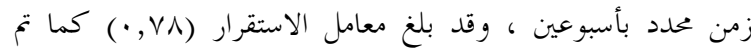

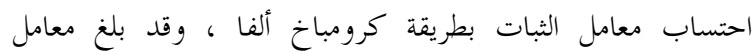
الاتساق الداخلي (T/,··) كما تم احتساب معامل الثبات بطريقة التجزئة النصفية ، حيث بلغ معامل الثبات النصفي (r/م, ·).
كالاهتمام بالتربية المهنية وإعادة إنعاش التربية الديمقراطية لإعطاء

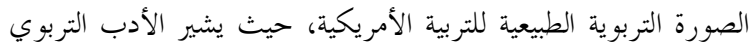

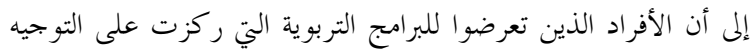

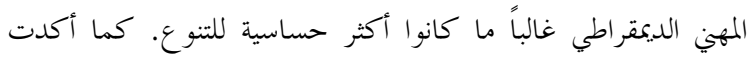

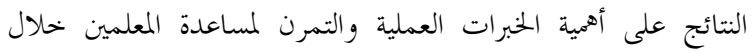
إعدادهم. وأظهرت النتائج أن تعريض المعلمين المباشر والهادف المافية

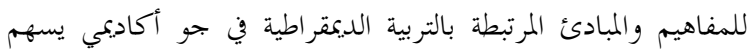
بشكل كبير في توظيف طرق التعليم البنائية الاستناجية مثل الاستكشاف والحوار والمناقشة، ويمكن أن يساعد في تعزيز المبادئ والقيم والديمقراطية العالمية والوعي السليم لفلسفة التربية.

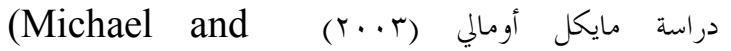
ب'Malley) للجميع".حيث ناقش الباحث موضوع التعليم غير الحكومي على أنه

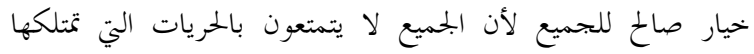

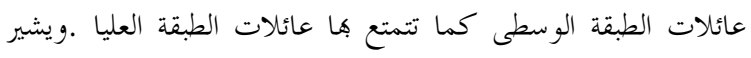

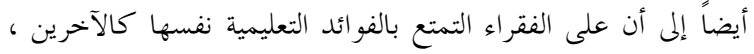

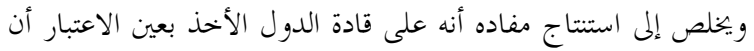

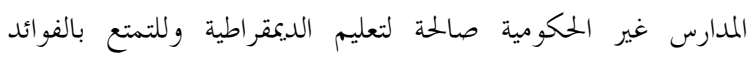

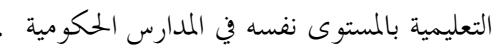
يلاحظ من الدراسات السابقة ما يلي : لئل - أجمعت الدراسات السابقة على أهمية ممارسة ديمقراطية التعليم

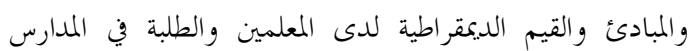

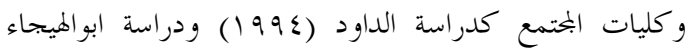

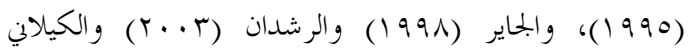

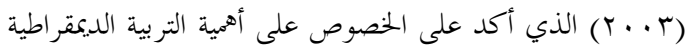

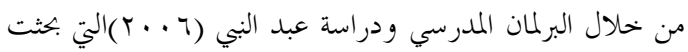
أسس التربية الديمقراطية عند طلبة المدارس .

في حين ركزت دراسة الصرايرة (V. . T) على معيقات التنمية السياسية في الأردن. وأشارت الدراسات الأجنبية على أهمية

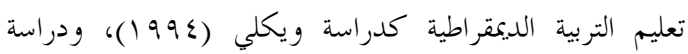

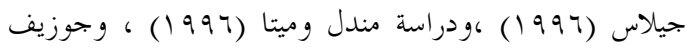

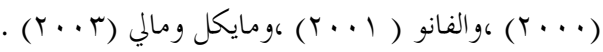

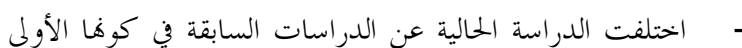
من نوعها كدراسة تطبيقية هدفت إلى تقصي وعي طلبة الجامعات الأردنية بمعيقات التربية الديمقراطية. 
Journal of Environmental Studies [JES] 2010. 4: 35- 57

Article

\begin{tabular}{|c|c|c|c|}
\hline النسبة \% & العدد & & \multirow{3}{*}{ الجنس } \\
\hline$\%$ or.^ & $r \varepsilon \varepsilon$ & ذكر & \\
\hline$\% \leq 7 . r$ & rq7 & أنثى & \\
\hline$\% 1 \cdots$ & $7 \varepsilon$ & \multicolumn{2}{|c|}{ المجموع } \\
\hline \% rr.o & $r \cdot \lambda$ & أولى & \multirow{4}{*}{ المستوى } \\
\hline$\% \leq 0.7$ & rqY & ثانية & \\
\hline$\% \backslash \leq . V$ & $9 \varepsilon$ & ثالثة & \\
\hline$\% \vee . r$ & $\varepsilon 7$ & رابعة & \\
\hline$\% 1 \cdots$ & $7 \varepsilon$. & \multicolumn{2}{|c|}{ المجموع } \\
\hline$\% \leq 7 . r$ & r97 & مدينة & \multirow{4}{*}{ ككان الإقامة } \\
\hline$\% r \cdot . \wedge$ & ITr & قرية & \\
\hline$\% 10.4$ & $9 V$ & بادية & \\
\hline$\% \backslash \vee . \wedge$ & $11 \varepsilon$ & مخيم & \\
\hline$\% 1 \cdots$ & $7 \varepsilon$. & \multicolumn{2}{|c|}{ المجموع } \\
\hline$\% 09.1$ & rVA & $y$ & \multirow{2}{*}{ العضوية } \\
\hline$\% \varepsilon \cdot .9$ & rTr & نعم & \\
\hline$\% 1 \ldots$ & $T \varepsilon$. & & \\
\hline
\end{tabular}

جدول (1) توزيع أفراد العينة حسب المتغيرات الديوجرافية قيد البحث في الدراسة

المترابطة وتحليل التباين، واختبار المقارنات البعدية لاستجابات الطلبة على

\section{نتائج الار اسة ومناقشتها}

بعد تغريغ البيانات اظهرت الدراسة النتائج التالية النتائج المتعلقة بالسؤال الأول والذي نصه: ما معيقات التربية الديمقراطية

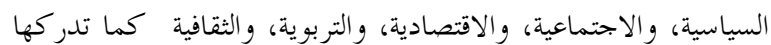

$$
\text { عينة من طلاب الجامعات الأردنية؟ }
$$

\section{أولا النتائج المتعلقة بمجال المعيقات السياسية:}

لإججابة عــن هذا السئال حسبت المتوسطات الحسابية والانحرافات المعيارية والأهمية النسبية للفقرات التي تقيس معيقات التربية الديمقراطية

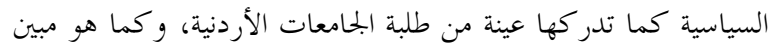
في جدول (r) و يتبين من الجدول رقم (r) أن المتوسطات الحسابية لمعيقات التربية الديمقراطية السياسية كما يتصورها طلبة الجامعات

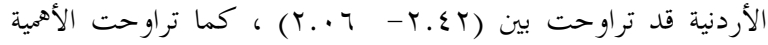

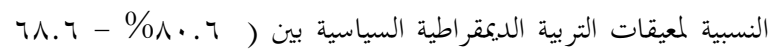

تم استخراج الدرجات على الاستبانة بترجمة سلم الإجابة اللفظي لكل فقرة إلى سلم تقديري رقمي مؤلف من ثلاث درجات: دائما(؟) ،

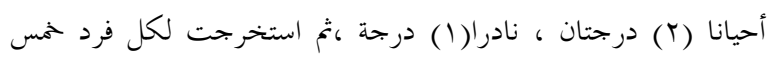
درجات على الاستبانة، تتمثل معيقات التربية الديمقراطية السياسية،والاجتماعية والاقتصادية ، و التربوية ، و الثقافية والدرجة الكلية

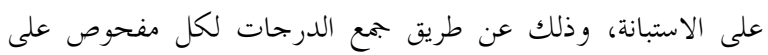
الفقرات التي تمثل المعيقات الكلية للتربية الديمقراطية ،حيث اعتمدت ولتئ الأهمية النسبية بدلالة الوسط الحسابي بمثابة درجات المعيقات على الفقرة

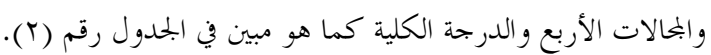
بحيث يتم إيجاد الأهمية النسبية للفقرة من خلال ضرب وسطها الحسابي

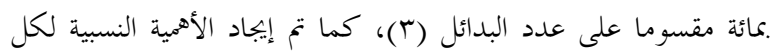

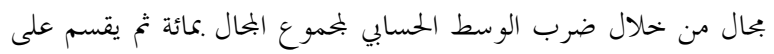
حاصل ضرب عدد البدائل (r) بعدد الفقرات.

\section{المعالجة الإحصائية}

لإإجابة عن أسئلة الدراسة تم تفريغ البيانات الواردة في الاستبانة،

وتحليلها إحصائياً ببرنامج (SPSS) كما استخدمت التهن التقنيات الإحصائية المناسبة لكل سئال من أسئلة الدراسة،مثل: المتوسطات

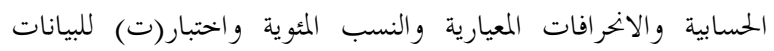


Journal of Environmental Studies [JES] 2010. 4: 35- 57

Article

\begin{tabular}{|c|c|c|c|c|c|c|}
\hline \multicolumn{2}{|c|}{ مرتفع } & \multicolumn{2}{|c|}{ متوسط } & \multicolumn{2}{|c|}{ منخفض } & \multirow[t]{2}{*}{ درجات التقييم } \\
\hline الأهمية النسبية & الوسط الحسابي & الأهمية النسبية & الوسط الحسابي & الأهمبة النسبية & الوسط الحسابي & \\
\hline \multirow[t]{6}{*}{$\% 1 \ldots-\% \vee \wedge$} & $r-r, r \leqslant$ & $\begin{array}{l}-\% 04 \\
\% \vee V, 74\end{array}$ & T.T - 1,TV & $\begin{array}{l}-\% \text { \% } \\
\text { \% }\end{array}$ & $1,77-1$ & الفقرة \\
\hline & $r \tau-r \Lambda$ & & $r V, q-r$. & & $19,9 r-1 r$ & معيقات سياسية \\
\hline & $\varepsilon \Lambda-r \vee, \varepsilon$ & & $r V, r-r V$ & & Y7,0-17 & و معيقات اجتماعية \\
\hline & rq- rA & & $r v, q-r$. & & $19,9 r-1 r$ & معيقات تربوية \\
\hline & $0 \leqslant-\varepsilon r$ & & $\leqslant 1,9-r$. & & $r q-11$ & معيقات ثقافية 1 ف 1 فقرة \\
\hline & $I V \leqslant-1 \Gamma_{0, V}$ & & $1 \pi 0,7-97,1$ & & $97, \vee-01$ & الارجة الكلية ^هـ \\
\hline
\end{tabular}

جدول رقم (r) درجات التقييم على مجالات معيقات التربية الديمقراطية والدرجة الكلية

\begin{tabular}{|c|c|c|c|c|c|c|}
\hline مستوى & الأهمية - النسبية & الاتحر اف & الحسابي & معيقات التربية الديمقر اطية السياسية & رالفة & 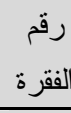 \\
\hline 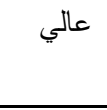 & $\% \wedge \cdot .7$ &. .77 & $r . \leqslant r$ & بعد التخر جناعة الطلبة بديمقر اطية المساو اة في سياسات التعبين في ضوء الكفاءة & 1 & $v$ \\
\hline 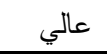 & $\% \vee \wedge$ & .70 & r.r & عدم الاستقر ار السباسي لدول الجوار • & r & 7 \\
\hline متوسط & $\% \vee \neg . r$ & .79 & r.rq & تقييد حرية التعبير عن الر أي داخل حرم الجامعات. & r & 1 \\
\hline منوسط & $\% \vee 0.7$ & $.7 r$ & r. TV & ضعف الوعي بالحقوق و الو اجبات السباسية عند الطلبة . & $\varepsilon$ & r \\
\hline متوسط & $\% \vee 0$ &. .79 & r. ro & تأثز الطلبة بتفاعلات الصر اع العربي الإسر ائبلي & 0 & $\varepsilon$ \\
\hline متوسط & $\% \vee \varepsilon . r$ &.$\vee r$ & r.rt & بجميع صورد والة الإحباط و اليأس عند الطلبة فيما يتعلق بمعالجة قضايا الفساد & 7 & ir \\
\hline متوسط & $\% \vee r .7$ &.$v r$ & r.r. & عدم تطبيق القانون في تحقيق العدالة بين الطلبة في الجامعات. & $\mathrm{v}$ & 1. \\
\hline 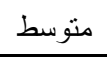 & $\% \vee r .7$ & .71 & r.ı & خلط العمل السياسي بالعمل المهني في الجامعات الأردنية . & $\wedge$ & $\wedge$ \\
\hline 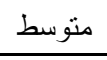 & $\% \vee r .7$ & .71 & r.ı & ضعف المؤسسات الديمقر اطية وتقصير ها في أداء أدو ارها الديمقر اطية. & 9 & 11 \\
\hline متوسط & $\% \vee r . r$ &.$v 1$ & r.IV & 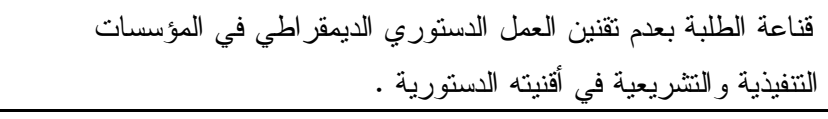 & 1. & 9 \\
\hline منوسط & $\% \vee r$ &.$V r$ & r.17 & منع الطلبة من ممارسة النشاطات السياسية داخل حرم الجامعات. & 11 & r \\
\hline متوسط & $\% \curlyvee \wedge .7$ &.$\vee r$ & r.. T & عدم احتر ام المدرسين لحقوق الطلبة السياسية . & ir & ○ \\
\hline منوسط & $\% \vee \varepsilon . r$ & r.99 & Yr.Vะ & 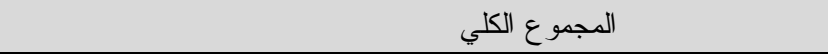 & & \\
\hline
\end{tabular}

جلول (r) المتوسطات الحسابية والاتحر افات المعيارية والأهمية النسبية لمعيقات التربية الايمقراطية السياسية كما يتصورها طلبة الجامعات الأردنية مرتبة تنازليا حسب الوسط الحسابي للفقرة 
النسبية لمعيقات التربية الديمقراطية الاجتماعية والاقتصادية بين (2) . \% \% . . - \% \% . . r

حيث جاءت الفقرة رقم(1) " عدم وجود المؤسسات الاجتماعية

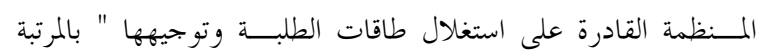

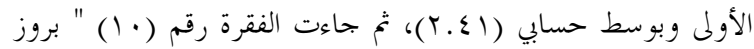

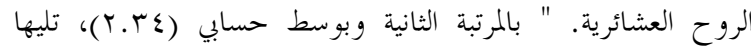

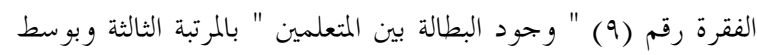

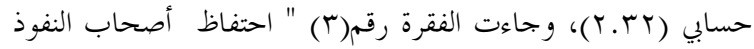

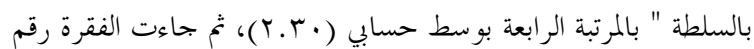

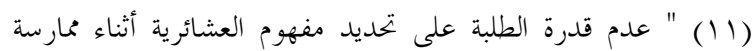

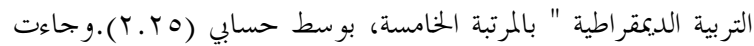
الفقرة رقم (ع) " شعور الطلبة باللامبالاة ابتاه القضايا الاجتماعية

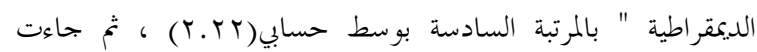

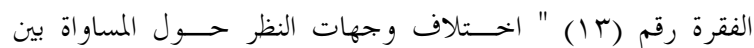

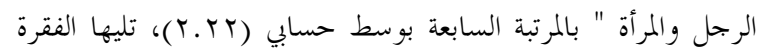
رقم (10) " عدم الاستقرار الاقتصادي للأسرة الأردنية " بالمرتبة

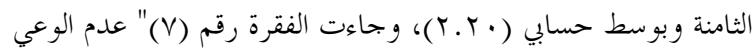

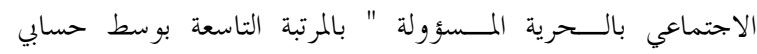

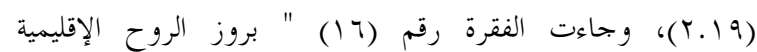

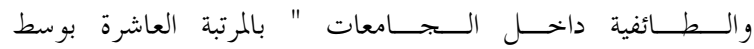

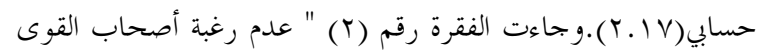

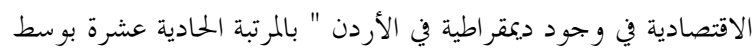
حسابي (Y.10)، ثم جاءت الفقرة رقم (ع () " سيطرة النظام الأبوي

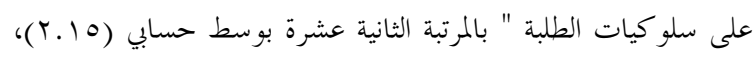
وجاءت الفقرة رقم (7) " غياب المشاركة التطوعية في الختمع المللي

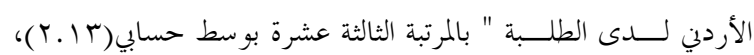

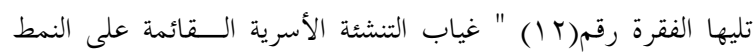

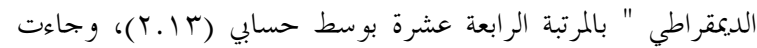

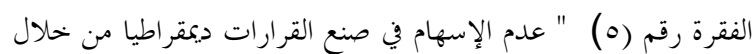
بحالس الطلبة " بالمرتبة الخامسة عشرة بوسط حسابي (T. (T. T). ثم جاءت الفقرة رقم (^) " انتشار الفساد المالي والإداري " بالمرتبة

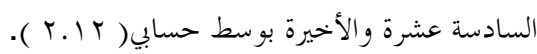

وقد جاءت أهم معيقات التربية الديمقراطية السياسية كانت في الفقرة

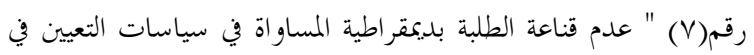

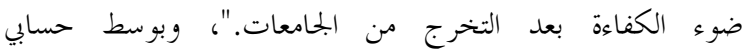

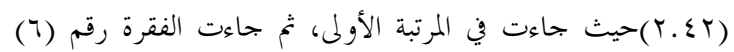

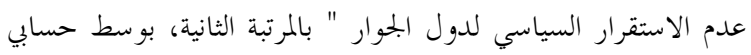

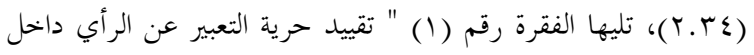

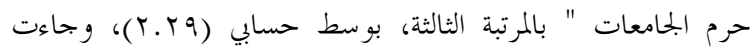

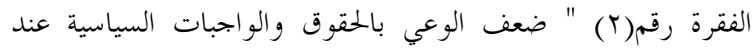

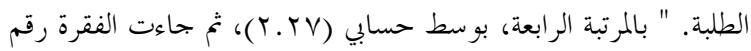

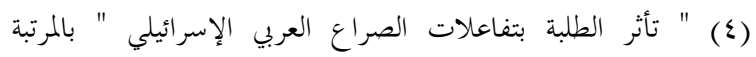

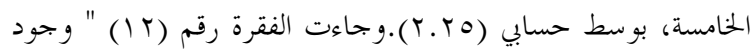

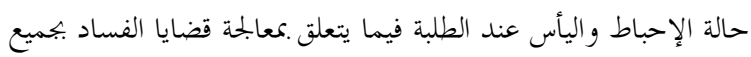

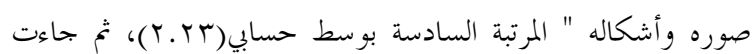
الفقرة رقم (• (1) " عدم تطبيق القانون في تحقيق العدالة بين الطلبة في

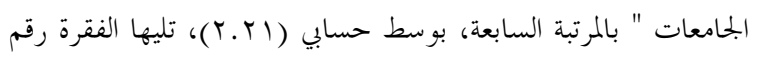

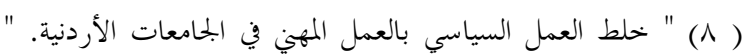

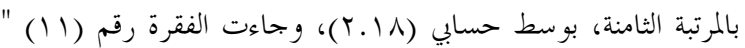

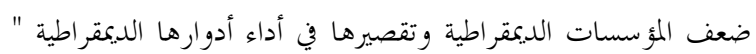

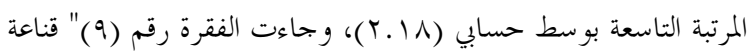
الطلبة بعدم تقنين العمل الدستوري الديمقراطي في المؤسسات التنفيذية

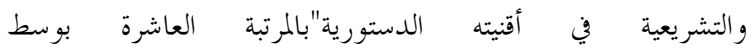

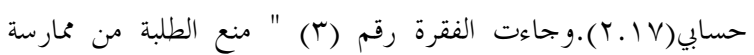

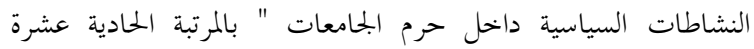

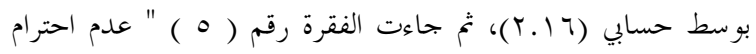
المدرسين لحقوق الطلبة السياسية . " بالمرتبة الثانية عشرة والأخيرة الخرات بوسط حسابي (T •.T).

\section{ثانيا النتائج المتعلقة بمجال (بلم) المعيقات الاجتماعية} و الاقتصادية.

للإجابة على هذا السؤال حسبت المتوسطات الحسابية والانخرافات المعيارية والأهمية النسبية للفقرات التي تقيس معيقات التربية الديمقراطية

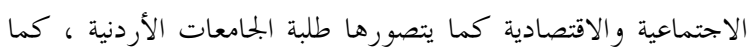
هو مبين في جدول (ع). يتبين من الجدول (ع) أن المتوسطات الحسابية لمعيقات التربية

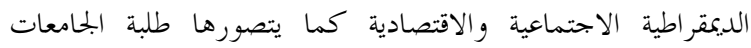

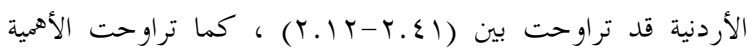


Journal of Environmental Studies [JES] 2010. 4: 35- 57

Article

\begin{tabular}{|c|c|c|c|c|c|c|}
\hline مستوى (الدور & الأهمية & المعياري & الحسابي & التربية الديمقر اطية الاجتماعية والاقتصادية & رتبة & 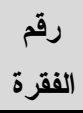 \\
\hline عالي & $\% \wedge \cdot . r$ & .0 & Y. $\leqslant 1$ & الطلبــة وجود المؤسسات الاجتماعية المــنظمة القادرة على استغلال طاقات & 1 & 1 \\
\hline 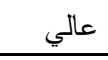 & $\% \vee \wedge$ &.$\vee v r$ & r.r & بروز الروح العشائرية. & r & 1. \\
\hline منوسط & $\% \vee V . r$ &..$v r$ & r.rt & وجود البطالة بين المتعلمين . & r & 9 \\
\hline منوسط & $\% \vee 7.7$ & $\because v$. & T.r. & احتفاظ أصحاب النفوذ بالسلطة. & $\varepsilon$ & r \\
\hline متوسط & $\% \vee 0$ &.$\vee \vee$ & T. YO & عدم قدرة الطلبة على تحديد مفهوم العشائرية أثناء ممارسة التربية الديمقر اطية . & ○ & 11 \\
\hline منوسط & $\% \vee \leqslant$ & $\because \times 1$ & t. rt & شعور الطلبة باللامبالاة اتجاه القضايا الاجتماعية الديمقر اطية. & 7 & $\varepsilon$ \\
\hline منوسط & $\% \vee \varepsilon$ & $\because v \cdot$ & r. rr & اخــتلاف وجهات النظر حــول المساو اة بين الرجل و المر أة . & $\checkmark$ & ir \\
\hline متوسط & \%VT.r &. .79 & r.r. & عدم الاستقر ار الاقتصادي للأسرة الأردنية . & $\wedge$ & 10 \\
\hline متوسط & $\% \vee r$ & $\because V r$ & r.19 & عدم الوعي الاجتماعي بالــــرية المـسؤولة . & 9 & $\checkmark$ \\
\hline 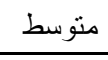 & \%VY.r & $\because \vee \wedge$ & r.IV & بروز الروح الإقليمية و الــطـــائفية داخــل الــــــامعات. & 1. & 17 \\
\hline 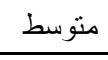 & $\% \vee 1.7$ & $\because \vee 1$ & r.10 & عدم رغبة أصحاب القوى الاقتصادية في وجود ديمقر اطية في الأردن . & 11 & r \\
\hline منوسط & $\% \vee 1.7$ & $\cdot . \mathrm{Vr}$ & r. 10 & سبطرة النظام الأبوي على سلوكيات الطلبة. & ir & $1 \leqslant$ \\
\hline منوسط & $\% \vee 1$ & $\because v \leqslant$ & r.IT & غياب المشاركة التطوعية في المجتمع المحلي الأردني لـــى الطلــــة . & וr & 7 \\
\hline متوسط & $\% \vee 1$ &. .79 & r.IT & غياب التششئة الأسرية الــقائمة على النمط الديمقر اطي. & $1 \leq$ & it \\
\hline منوسط & $\% \vee 1$ & $\because \times 1$ & r.IT & عدم الإسهام في صنع القرارات ديمقر اطيا من خلال مجالس الطلبة . & 10 & ० \\
\hline منوسط & $\% \vee \cdot .7$ & $\cdot . v r$ & r.IT & انتشار الفساد المالي و الإداري • & 17 & $\wedge$ \\
\hline متوسط & \%Vr.V & $\varepsilon . \vee$ & ro.si & \multicolumn{3}{|l|}{ 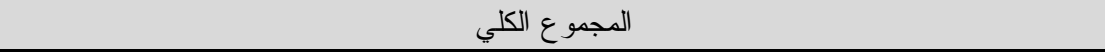 } \\
\hline
\end{tabular}

جدول (؛) المتوسطات الحسابية والاحر افات المعيارية والأهمية النسبية لمعيقات التربية الايمقراطية الاجتماعية والاقتصادية كما يتصورها طلبة الجامعات الأردنية مرتبة تنازليا حسب الوسط الحسبه الحسبي للفقرة

عدم تكافؤ الفرص التعليمية لجميع الأردنيين للدراسة في الجامعات "

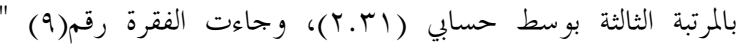

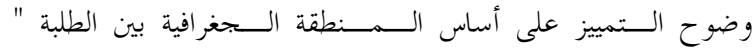

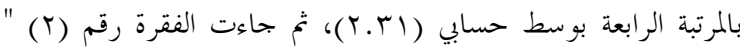

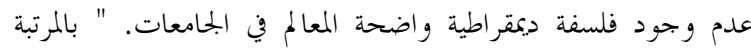

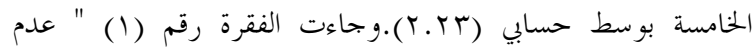

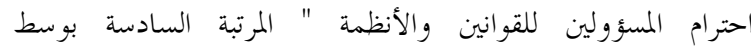

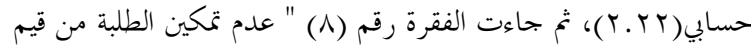

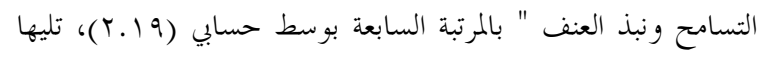
الفقرة رقم (ع) " ضعف التركيز على وجود مناهج لتدريس التربية

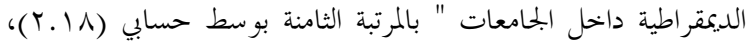
وجاءت الفقرة رقم (V) " ضـــف الإيمان بــأن التربيسة هي أداة

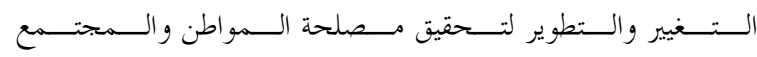

\section{ثالثا النتائج المتعلقة بمجال المعيقات التربوية.} للإجابة على هذا السؤال حسبت المتوسطات الحسابية والانحرافات المعيارية والأهمية النسبية للفقرات التي تقيس معيقات التربية الديمقراطية

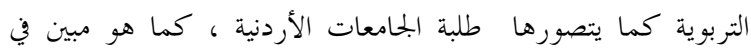
الجدول رقم (0) يتبين من الجحدول رقم (0) أن المتوسطات الحسابية لمعيقات التربية

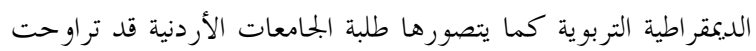

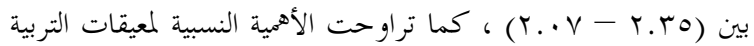

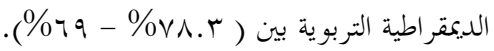
حيث جاءت الفقرة رقم(ץ) " ضعف التنشئة التربوية على المشاركة في السلطة والتشاور معها. " بالمرتبة الأولى بوسط حسابي (ب. (Y))، وجاءت الفقرة رقم (0) " تركيز المناهج على التربية التقليدية "التلقين

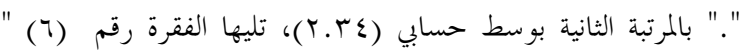


Journal of Environmental Studies [JES] 2010. 4: 35- 57

Article

المسؤولية عند طلبة الجامعات." بالمرتبة الثانية عشرة والأخيرة بوسط

حسابي (Y. V. (Y).

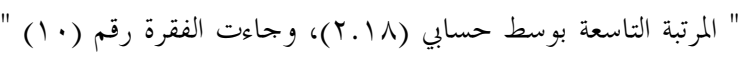

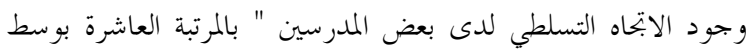

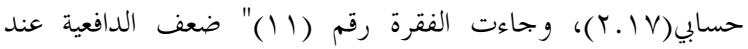

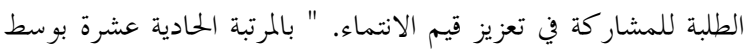

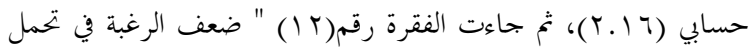

\begin{tabular}{|c|c|c|c|c|c|c|}
\hline مستوى الدور & الأهمية & المعياري & الوسابط & معيقات التربية الديمقراطية التربوية & 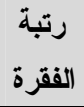 & 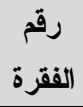 \\
\hline 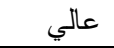 & $\% \vee \wedge . \Gamma$ & $1.1 \leq$ & r.to & ضعف التشتئة التربوية على المشاركة في السلطة و النشاور معها. & 1 & r \\
\hline عالي & $\% \vee \wedge$ &.$V r$ & T.TE & تركيز المناهج على التزبية التقليدية "التلقين ". & r & ○ \\
\hline منوسط & $\% \vee \vee$ & $\cdot v \cdot$ & r.M & عدم تكافؤ الفرص التعليمية لجميع الأردنيين للار اسة في الجامعات. & r & 7 \\
\hline 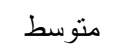 & $\% \vee \vee$ &.$V r$ & T.M & وضوح الــتمييز على أساس الــــــنطقة الــــغر افية بين الطلبة . & $\varepsilon$ & 9 \\
\hline منوسط & $\% \vee \leq . r$ & r & t.tr & عدم وجود فلسفة ديمقر اطية و اضحة المعالم في الجامعات. & ○ & r \\
\hline 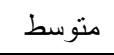 & $\% \vee \varepsilon$ & $\cdot . v r$ & t.rt & عدم احتر ام المسؤولين للقو انين و الأنظمة . & 1 & 1 \\
\hline 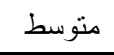 & $\% \vee r$ & $\cdot \cdot v 1$ & r.19 & عدم تمكين الطلبة من قيم التسامح ونبذ العنف . & $\checkmark$ & $\wedge$ \\
\hline منوسط & $\% \vee r .7$ & $\cdot \cdot v 1$ & r.11 & ضعف التركيز على وجود مناهج لتدريس التربية الديمقر اطية داخل الجامعات & $\wedge$ & $\varepsilon$ \\
\hline متوسط & $\% \vee Y .7$ & $\cdot v \cdot$ & r.11 & 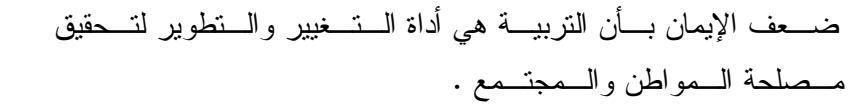 & 9 & V \\
\hline 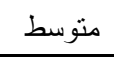 & $\% \vee r . r$ & $\because v 1$ & r.IV & وجود الاتجاه التسلطي لاى بعض المدرسين . & 1. & 1. \\
\hline 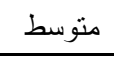 & $\% \vee r$ &. .79 & $r .17$ & ضعف الدافعية عند الطلبة للمشاركة في تعزيز قيم الانتماء. & 11 & 11 \\
\hline 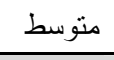 & $\%$ \% & $\because$ Vo & r...V & ضعف الرغبة في تحمل المسؤولية عند طلبة الجامعات. & ir & Ir \\
\hline 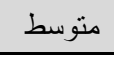 & $\% \vee \varepsilon . r$ & $\varepsilon . r$ & rT.VT & 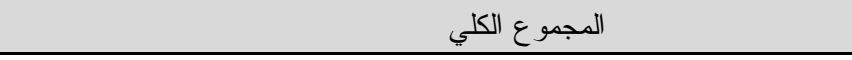 & & \\
\hline
\end{tabular}

جدول (0) المتوسطات الحسابية والانحر افات المعيارية والأهمية النسبية لمعيقات التربية الديمقراطية التربوية كما يتصورها طلبة الجامعات الأردنية مرتبة تنازليا حسب الوسط الحسابي للفقرة

جاءت الفقرة رقم (10) " عدم قدرة الجامعة كمؤسسة ثقافية وتربوية

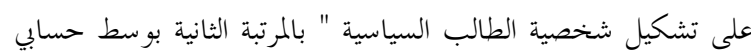

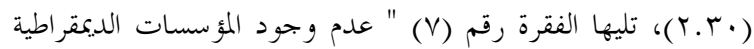

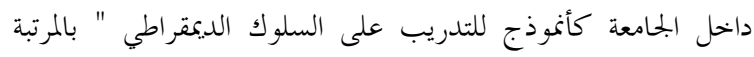

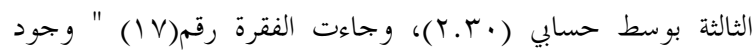

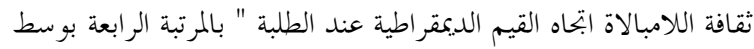

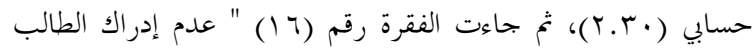

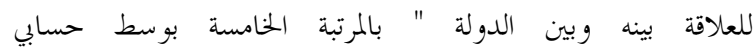

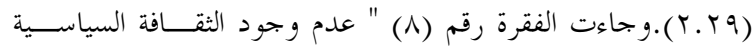

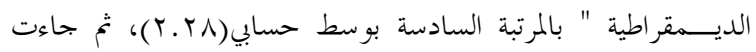

\section{رابعا النتائج المتعلقة بمجال المعيقات الثقافية.} للإجابة عــن هذا السؤال حسبت المتوسطات الحسابية والانخرافات

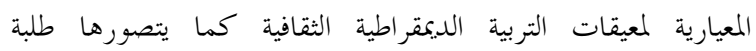

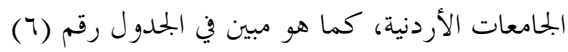
يتبين من الجحدول رقم (T) أن المتوسطات الحسابية لمعيقات التربية

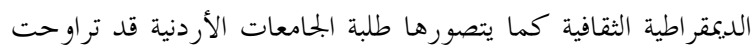

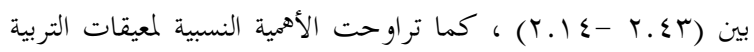

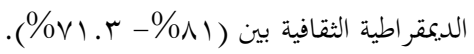

حيث جاءت الفقرة رقم(1) " ضعف القيم والمبادئ الثقافية

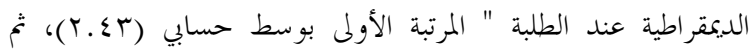


إضافة إلى وجود توغل في سياسات التعين في الدولة من قبل السلطة التنفيذية ، وعدم احترامها للكفاءات العلمية وأن عامل الواسطة والمسوبية ووراثة المناصب وخصوصا العليا منها في الدولة الأردنية وهو مفصل مهما في الحياة الديمقراطية وهو دلالة واضحة على شعور

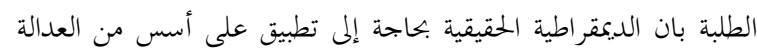

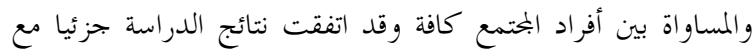

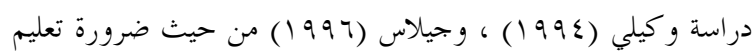

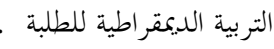

في حين حصلت الفقرة رقم (0)"عدم احترام المدرس لحقوق الطلبة

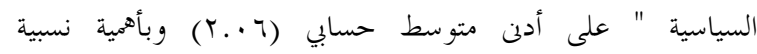

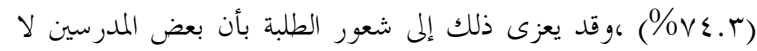

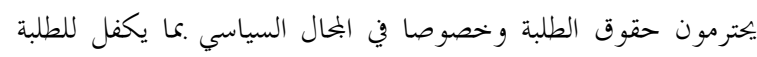

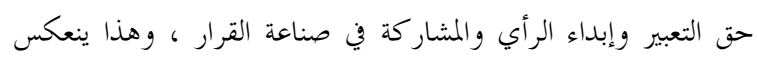

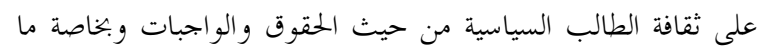

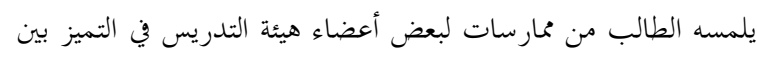

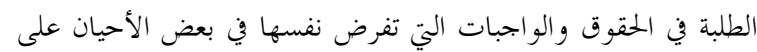

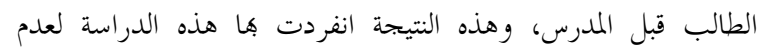

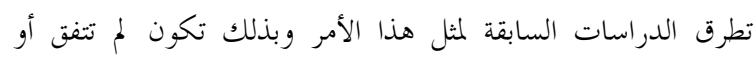
تختلف فيه مع أية دراسة سابقة وتفردها هذا يزيدها خصوصية عن تلك الك

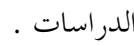

كذلك أظهرت نتائج الدراسة فيما يتعلق .معيقات التربية

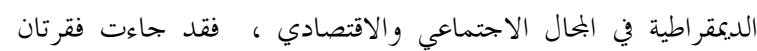

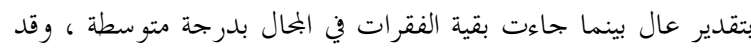

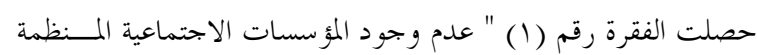

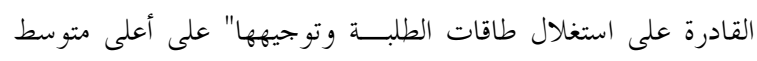

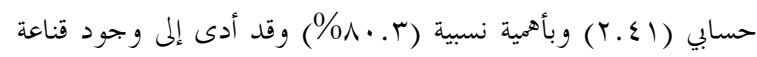

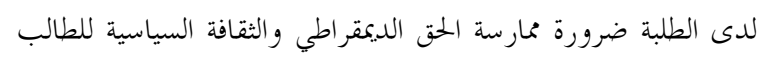
من خلال تلك المؤسسات غير الموجودة في المختمع المدني والمختمع الرسمي ، اذ لو كانت موجودة وعاملة وقادرة على استغلال قدرات

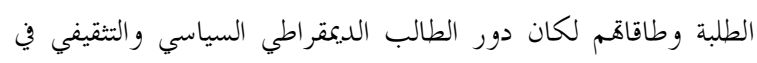

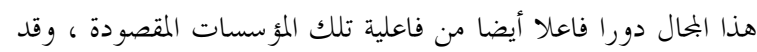

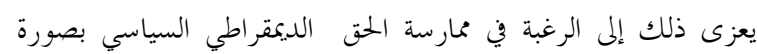

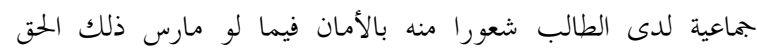
بشكل منفرد . ـوقد اتفقت نتيجة الدراسة جزئيا مع دراسة حمادة

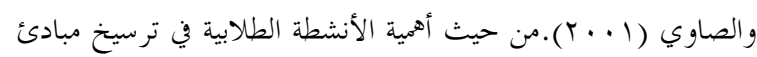

الفقرة رقم (Y) " عدم بتسيد مبدأ الوعي في البحالات الثقافية بين

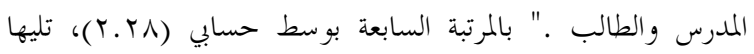
الفقرة رقم (r) " ضعف استيعاب الطلبة للشعارات الوطنية ومدلولاتها

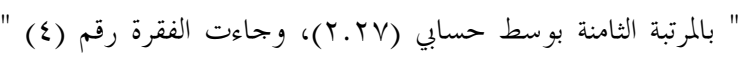
عدم قدرة المدرسين على توليد المشاعر والأحاسيس للشعور بالمواطنة

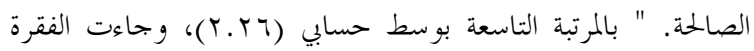

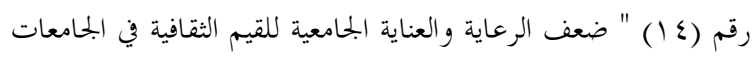

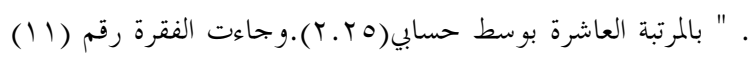

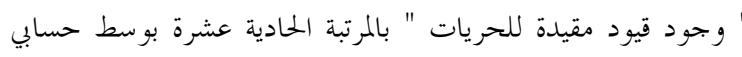

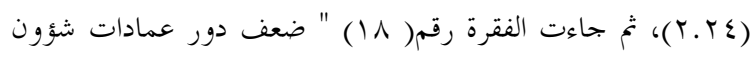
الطلبة في تنمية الحس الديمقراطي بين الطلبة " بالمرتبة الثانية عشرة

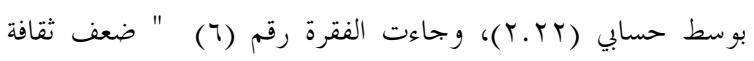

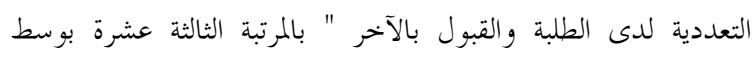

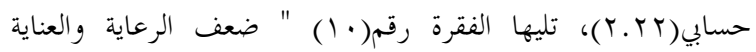

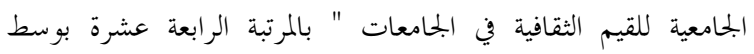

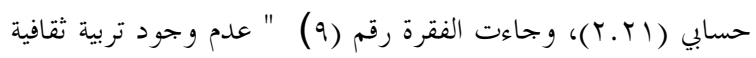

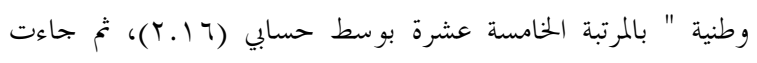
الفقرة رقم (Y I ) " ضعف القيم لدى الطلبة التي تؤمن بالاندماج

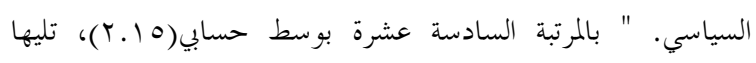

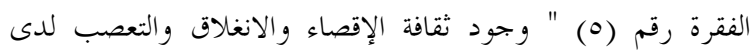

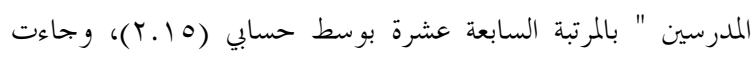
الفقرة رقم (r (I) " ضعف وسائل الإعلام في إنضاج الوعي بالتربية

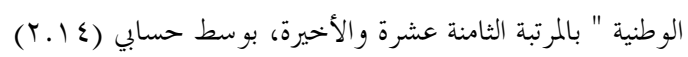
أظهرت نتائج الدراسة فيما يتعلق .كعيقات التربية الديمقراطية السياسية أن تقدير درجة عينة الدراسة جاءت بدرجة عالية في فقرتين

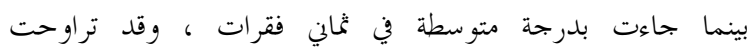

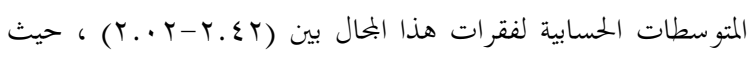
جاءت الفقرة رقم (V) و التي تنص على :" عدم قناعة الطلبة بديمقراطية

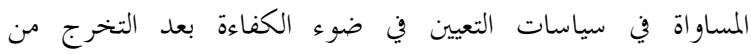

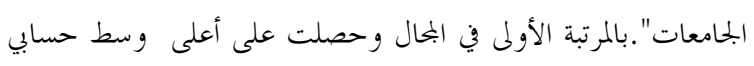

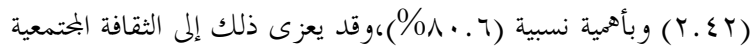

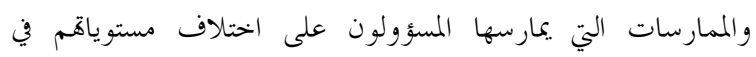

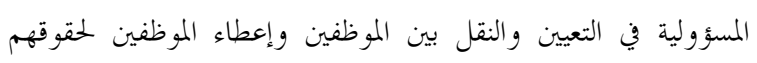

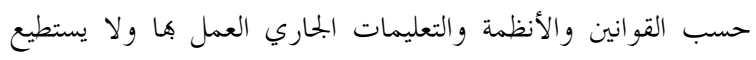

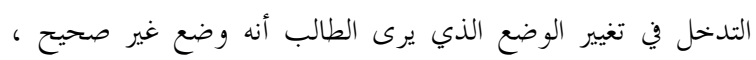


Journal of Environmental Studies [JES] 2010. 4: 35- 57

Article

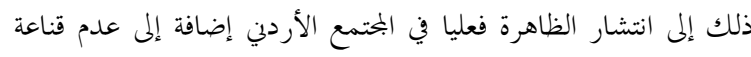

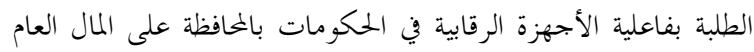
بشكل سليم حيث لم تقم الحكومات المتعاقبة بكحاسبة بعض المسؤولين

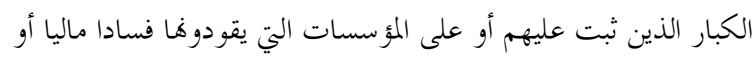

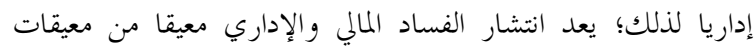

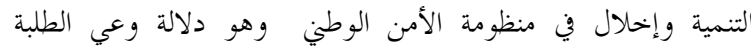
بضرورة القضاء على هذه الظاهرة . عدا عن ذلك فلا شك فل في أنه

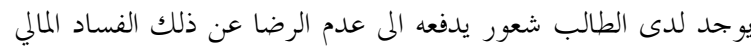

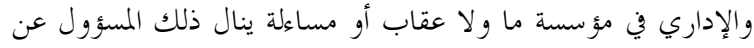
ذلك الفساد

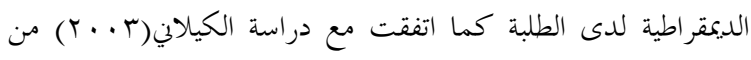
ضرورة وجود البرلمان المدرسي الذي عمل على دعم الأنشطة

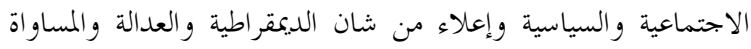

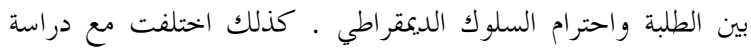

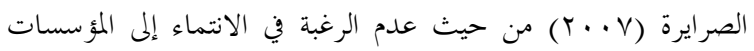

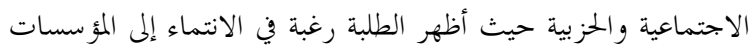

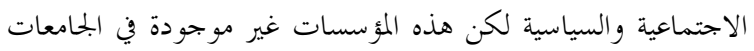

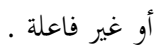

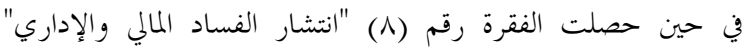

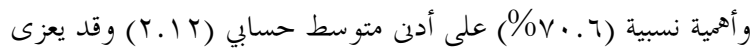

\begin{tabular}{|c|c|c|c|c|c|c|}
\hline مستوى & الأهمية & 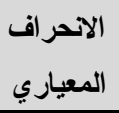 & الوسابي & التربية الديمقراطية الثقافية & 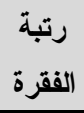 & 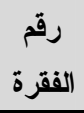 \\
\hline عالي & $\% \wedge 1$ & $.7 \varepsilon$ & $r . \leqslant r$ & ضعف القيم و المبادئ الثقافية الديمقر اطية عند الطلبة. & 1 & 1 \\
\hline متوسط & $\% \vee 7.7$ &. .79 & r.r. & عدم قدرة الجامعة كمؤسسة نقافية وتربوية على نتشكيل شخصية الطالب السياسية & r & 10 \\
\hline 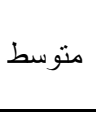 & $\% \vee 7.7$ & $\cdot . v r$ & r.r. & الديمقر اطي وجود المؤسسات الديمقر اطية داخل الجامعة كأنموذج للتدريب على السلوك & r & $\checkmark$ \\
\hline 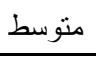 & $\% \vee 7.7$ &. $.7 \mathrm{~V}$ & r.r. & وجود ثقافة اللامبالاة اتجاه القيم الديمقر اطية عند الطلبة . & $\varepsilon$ & iv \\
\hline 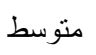 & $\% \vee \neg . \Upsilon$ &.$v 1$ & r.rq & عدم إدر الك الطالب للعلاقة بينه وبين الدولة . & $\circ$ & 17 \\
\hline متوسط & $\% \vee 4$ &. .79 & t.r人 & عدم وجود الثقــافة السياســـية الديـــقر اطية . & 7 & $\wedge$ \\
\hline 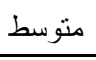 & $\% \vee 4$ & $.7 \varepsilon$ & r.r人 & عدم تجسيد مبدأ الوعي في المجالات التقافية بين المدرس و الطالب . & $\checkmark$ & r \\
\hline متوسط & $\% \vee 0.7$ & $\because v \cdot$ & t.rV & ضعف استيعاب الطلبة للشعار ات الوطنية ومدلو لاتها. & $\wedge$ & r \\
\hline 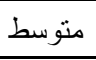 & $\% \vee 0 . r$ &. $.7 \mathrm{~V}$ & T.YT & عدم قدرة المدرسين على توليد المشاعر و الأحاسبس للشعور بالمواطنة الصالحة. & 9 & $\varepsilon$ \\
\hline 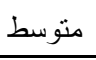 & $\% \vee 0$ &. .71 & T.YO & غياب دور المثقف القدوة كعامل أساسي في الحر الك الديمقر اطي . & 1. & $1 \varepsilon$ \\
\hline متوسط & $\% \vee \leqslant .7$ & $\cdot . V r$ & T.Y $\leqslant$ & وجود قيود مقيدة للحريات. & 11 & 11 \\
\hline متوسط & $\% \vee \varepsilon$ & $\cdot V \vee$ & t.rt & ضعف دور عمادات شؤون الطلبة في تتمبة الحس الديمقر اطي بين الطلبة . & ir & 11 \\
\hline متوسط & $\% \vee \leqslant$ &. .79 & t.r. & ضعف ثقافة التعددية لدى الطلبة و القبول بالآخر . & ir & 7 \\
\hline 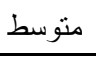 & \%Vr.t & $\cdot \cdot v r$ & $r . r_{1}$ & ضعف الرعاية و العناية الجامعية للقيم التقافية في الجامعات . & $1 \varepsilon$ & 1. \\
\hline 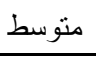 & $\% \vee r$ & $\cdot \vee \vee 4$ & $r .17$ & عدم وجود تربية نقافية وطنية . & 10 & 9 \\
\hline 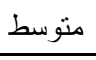 & $\% \vee 1.7$ &. .79 & $r .10$ & ضعف القيم لدى الطلبة التي تؤمن بالاندماج السياسي. & 17 & Ir \\
\hline 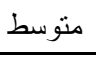 & $\% \vee 1.7$ & $\cdot \vee{ }^{\circ}$ & $r .10$ & وجود ثقافة الإقصاء و الانغلاق و التعصب لدى المدرسين . & IV & 0 \\
\hline متوسط & $\% \vee 1 . r$ & $\cdot . v r$ & r.l $1 \varepsilon$ & ضعف وسائل الإعلام في إنضاج الوعي بالتربية الوطنية . & 11 & IT \\
\hline متوسط & $\% \vee \leqslant .9$ & 0.9 & $\leqslant \ldots \leqslant 0$ & \multicolumn{3}{|l|}{ المجموع الكلي } \\
\hline
\end{tabular}

جدول (†) المتوسطات الحسابية و الاحر افات المعيارية والأهمية النسبية لمعيقات التربية الايمقراطية الثقافية مرتبة تنازليا حسب الوسط الحسابي للفقرة 
المناهج والمقررات المدرسية ومن ثم الجامعية والتي لم تتمكن من التغلب

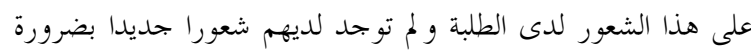
اقتفاء المعلمين في المدارس والمدرسين في الجامعات كقدوة يجتذى حذوه ضنا من الطلبة أن أوليكك المعلمين والمدرسين يفتقرون صميم القيمة القدوة والى أساليب التدريس التي تدعو الطلبة إلى الوعي الثقافي والى الى الثران تككينهم من الثقافة المجتمعية الصحيحة وتمكينهم من التمييز بين الأصيل والدخيل منا يخلق لديهم شعورا مؤداه عدم الاكتراث وعدم الاهتمام بالقيم والثقافة الأصيلة والدخيلة في آن واحد معا ، ولذلك كانت القناعة لدى الطلبة تتولد تدريجيا بترك الأصيل ونبذ الدخيل والبحث الديل

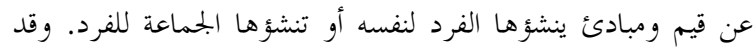

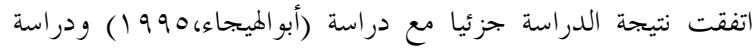

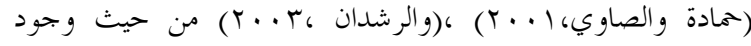
سلبيات في التجربة الديمقراطية وأهمية القيم والمبادئ الديمقراطية في المانيان

$$
\text { العملية التربوية . }
$$

في حين حصلت الفقرة رقم (r I )" ضعف وسائل الإعلام في إنضاج

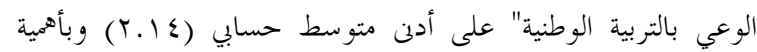

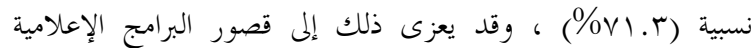

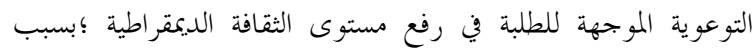

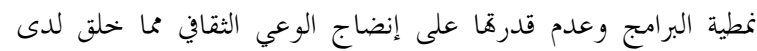
الطلبة دورا ضعيفا في تكوين الفكر الثقافي لديهم ، ويعزى ذلك أيضا الثاعيا

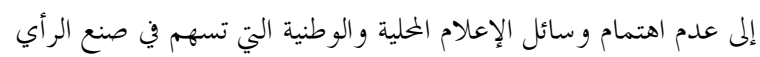

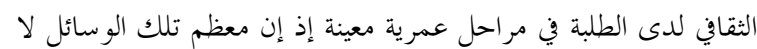

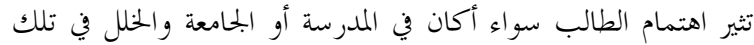

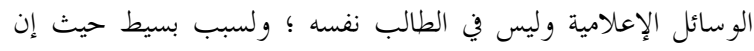

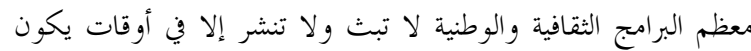
فيها الطالب على مقاعد الدرس في الجامعة . السؤال الثاني والذي نصه: هل توجد فروق ذات دلالة إلتالت إحصائية بين متوسطات درجات طلاب العينة في معيقات التربية الديمقراطية تبعاً لاختلاف بعض المتغيرات الديموجرافية : ( الجنس، المستوى الدراسي، مكان الإقامة، العضوية في إحدى الجمعيات أو الاتحادات الطلابية)

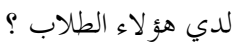
أولا : الجنس :هل توجد فروق ذات دلالة إحصائية عند مستوى

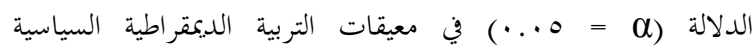
والاجتماعية والاقتصادية والتربوية والثقافية تعزى إلى متغير الجنس؟ الته
وقد أظهرت نتائج الدراسة أن درجة تقدير عينة الدراسة على معيقات

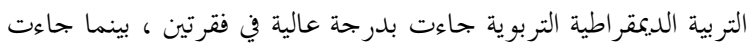
بدرجة متوسطة في باقي فقرات البحال ، وقد تراوحت المتوسطات

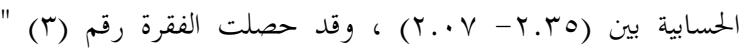

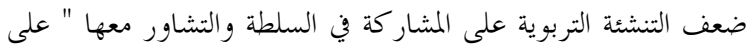

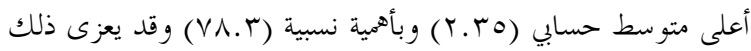

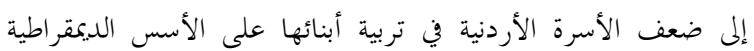

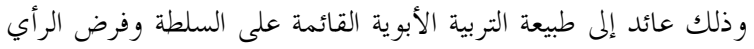

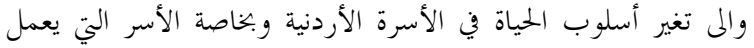

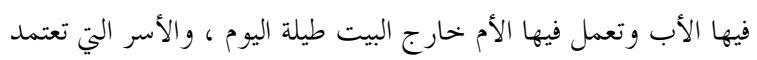

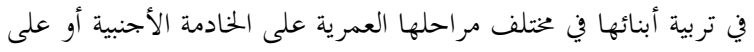
حاضنات الأطفال ورياضهن ، إضافة إلى عدم قناعة الطلبة بديمقراطية التشاور ، وقد اتفقت نتيجة الدراسة جزئيا مع دراسة (الدواد الداديات

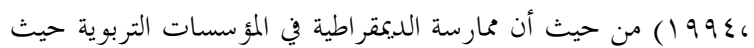
جاءت بدرجة متوسطة من وجهة نظر الطلبة .

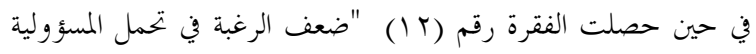
عند طلبة الجامعات" على أدنى متوسط حسابي في البحال (Y..V)

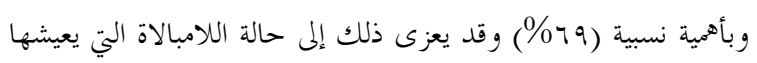
أغلب الطلبة وعدم الرغبة في تحمل المسؤولية نتيجة التنشئة والتربية

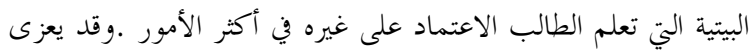

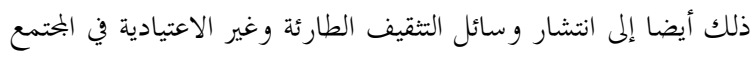

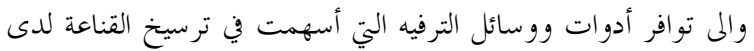
الطالب بضرورة المروب من المسؤولية واللجوء إلى الترفيه لتحقيق ذاته دون الشعور بالمشار كة في المسؤولية ابحاه الأسرة أو البختمع .

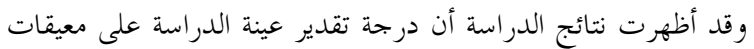
التربية الديمقراطية الثقافية جاءت بدرجة عالية في فقرة واحدة بينما

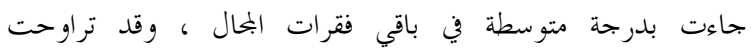

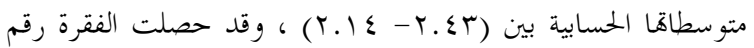
(1)" ضعف القيم والمبادئ الثقافية الديمقراطية عند الطلبة" على أعلى ألى

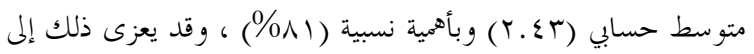
وعي الطلبة بأهمية الثقافة الديمقراطية إذ يشعر الطلبة بأن هنالك حالة التهالة جهل لديهم بحقوقهم الثقافية الديمقراطية وهي تشكل لهم تصورا

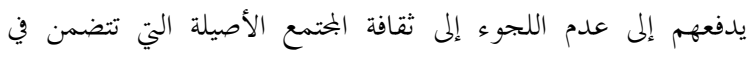

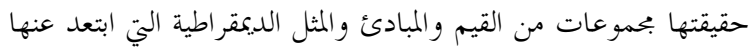

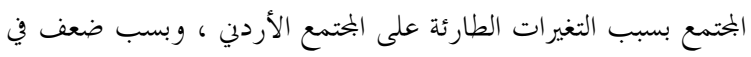


Journal of Environmental Studies [JES] 2010. 4: 35- 57

Article

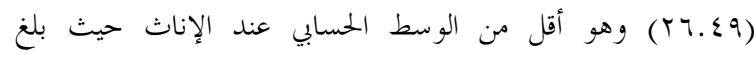

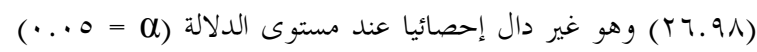

،أما المعيقات الثقافية فقد كان الوسط الحسابي عند الذكور (r....؟

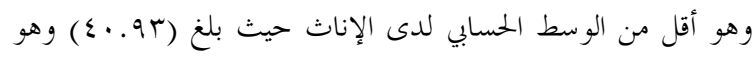

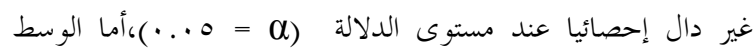

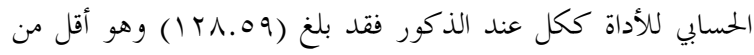

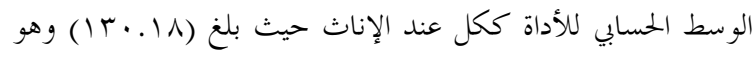

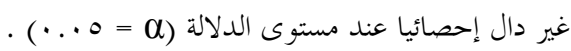

يتبين من الجدول رقم (V) أن الوسط الحسابي لمعيقات التربية

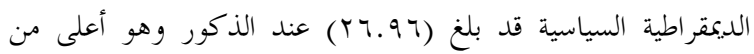

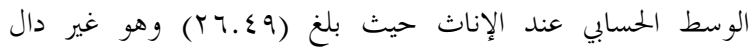

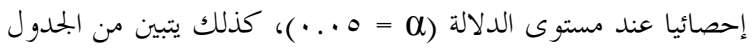
أن الوسط الحسابي لمعيقات التربية الديمقراطية الاقتصادية والاجتماعية قد بلغ (·. (1) وهو أقل من الوسط لدى الإناث حيث بلغ (Yo.VV)

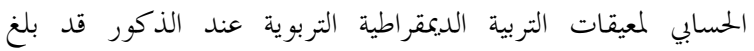

\begin{tabular}{|c|c|c|c|c|c|c|c|}
\hline الإحصائية & الحرية & قيمة T & الانحراف & الحسابي الوسط & العدد & الجنس & المعيقات \\
\hline \multirow{2}{*}{ צחו } & \multirow[t]{2}{*}{ תו } & \multirow[t]{2}{*}{$1 . \leqslant 91$} & $\varepsilon . .7$ & r7.97 & $r \leq \varepsilon$ & ذكور & \multirow{2}{*}{ السياسية } \\
\hline & & & r.9. & Y૫. $\{9$ & r97 & إناث & \\
\hline \multirow{2}{*}{$\because \cdot v V$} & \multirow[t]{2}{*}{ רו } & \multirow{2}{*}{$-1 . V \times 1$} & s.Vo & ro.1. & $r \leq \varepsilon$ & ذكور & \multirow{2}{*}{ والاقتصادية } \\
\hline & & & $\varepsilon . V T$ & ro.vV & r৭7 & إناث & \\
\hline \multirow{2}{*}{ צו } & \multirow[t]{2}{*}{ TrA } & \multirow[t]{2}{*}{$-1 . \leq 9 \leq$} & 0.10 & rT. $\leqslant 9$ & $r \leq \varepsilon$ & ذكور & \multirow{2}{*}{ التربوية } \\
\hline & & & T.V $\varepsilon$ & r7.91 & r97 & إناث & \\
\hline \multirow[t]{2}{*}{.000} & \multirow[t]{2}{*}{ או } & \multirow[t]{2}{*}{$-1.9 r \pi$} & $0.9 \varepsilon$ & $\varepsilon \ldots . r$ & $r \leq \varepsilon$ & ذكور & \multirow{2}{*}{ الثقافية } \\
\hline & & & 0.17 & $\varepsilon \cdot .9 r$ & rq7 & إناث & \\
\hline \multirow[t]{2}{*}{.100} & \multirow[t]{2}{*}{ Tr人 } & \multirow[t]{2}{*}{$-1 . \leqslant Y 0$} & $1 \varepsilon .1$ & $1 \% 1.09$ & $r \leq \varepsilon$ & ذكور & \multirow{2}{*}{ الاداة ككل } \\
\hline & & & IT.T & 1r...1 & r97 & إناث & \\
\hline
\end{tabular}

جدول (V) نتائج فحص الفروق في معيقات التربية الايمقراطية التي تعزى إلى متغير الجنس (T-test)

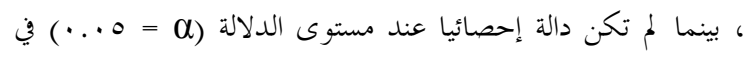
المعيقات الثقافية، وكذلك يتبين من الجددول عدم وجود فروق إحصانيا عند ذات

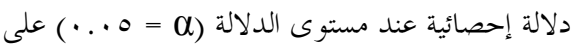

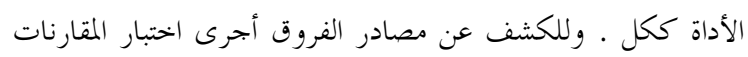

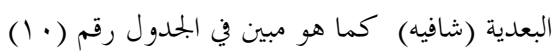

نلاحظ من الجحدول رقم (•) (1) أن معيقات التربية الديمقراطية

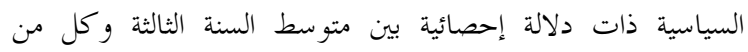
متوسط السنة الأولى والثانية ولصالح السنة الثالثة حيث بلغ متوسطاها (Y.90) بينما كان متوسط السنة الأولى (Y. (Y.9) والسنة الثانية

أما بالنسبة للمعيقات الاقتصادية والاجتماعية يتبين من الجدول رقم(•) إن هنالك فروقا ذات دلالة إحصائية بين مستوى السنة
ثانيا: المستوى الدراسي

هل توجد فروق ذات دلالة إحصائية عند مستوى الدلالة (م) ه... ) في معيقات التربية الديمقراطية السياسية والاجتماعية والاقتصادية والتربوية والثقافية تعزى إلى متغير المستوى الدراسي؟ للإجابة عن هذا السؤال حسبت المتوسطات الحسابية والانخرافات

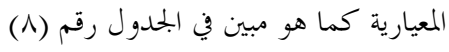
يتبين من الجحدول رقم (^) وجود فروق بين المتوسطات الحسابية حسب متغير المستوى الدراسي ولمعرفة دلالة الفروق بين المتوسطات

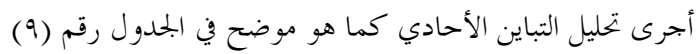

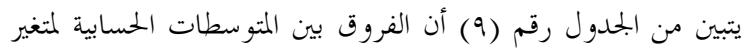
المستوى الدراسي دال إحصائيا عند مستوى الدلالة (م = ه . . •) في معيقات التربية الديمقراطية السياسية والاجتماعية والاقتصادية والتربوية 
Journal of Environmental Studies [JES] 2010. 4: 35- 57

Article

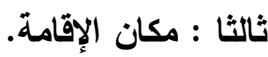

هل توجد فروق ذات دلالة إحصائية عند مستوى الدلالة (م)

ه . . • ) في معيقات التربية الديمقراطية تعزى إلى متغير مكان الإقامة ؟ للإجابة على هذا السؤال حسبت المتوسطات الحسابية والانخرافات

المعيارية كما هو مبين في الجحدول رقم (11)
الأولى وكل من السنة الثانية والثالثة والرابعة لصالح السنة الرابعة حيث

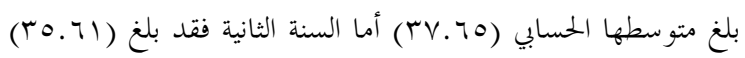

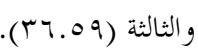
كذلك يتضح من الجدول رقم(• (1) إن معيقات التربية الديمقراطية التربوية ذات دلالة إحصائية بين متوسطات السنة الرابعة وكل من رنم متوسطات السنة الأولى والثانية ولصالح السنة الرابعة حيث بلغ

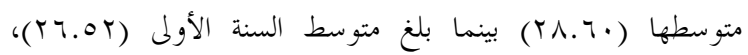

\begin{tabular}{|c|c|c|c|c|}
\hline الآحراف المعياري & الوسط الحسابي & العدد & المستوى & المعيقات \\
\hline$\{. .0$ & $r v . . q$ & $r \cdot \Lambda$ & أولى & \multirow{5}{*}{ السياسية } \\
\hline r.Ат & r..人9 & rar & ثانية & \\
\hline r.یI & ro. $\leqslant 1$ & $9 \leq$ & ثالثة & \\
\hline ะ.ะ૫ & $r 7.90$ & $\leq 7$ & رابعة & \\
\hline r.99 & YY.V & $T \leqslant$. & المجموع & \\
\hline 纟.VV & $r \leqslant . . \wedge$ & $r \cdot \Lambda$ & أولى & \multirow{5}{*}{ والاجتماعية } \\
\hline «، & ro.71 & rqr & ثانية & \\
\hline 0.1 . & $r 7.09$ & $9 \leq$ & ثالثة & \\
\hline 纟.7 & rV.To & $\leq 7$ & ر رابعة & \\
\hline$\varepsilon . \vee 7$ & ro.si & $T \leq$. & المجموع & \\
\hline$\varepsilon . .9$ & r..0Y & $r \cdot \Lambda$ & أولى & \multirow{5}{*}{ التربوية } \\
\hline$\varepsilon .11$ & r..or & rqr & ثانية & \\
\hline E.ケ人 & rч.А. & $9 \leq$ & ثالثة & \\
\hline$\varepsilon . \leqslant r$ & үᄉ. . & $\leq 7$ & رابعة & \\
\hline 纟.r। & r..VY & $T \leq$. & المجموع & \\
\hline $0 . \wedge \mathrm{V}$ & $\varepsilon \cdot . r T$ & $r \cdot \Lambda$ & أولى & \multirow{5}{*}{ الثقافية } \\
\hline $0.0 r$ & $\varepsilon . . V V$ & rar & ثانية & \\
\hline אד.ד & $\varepsilon \ldots \mid v$ & $9 \leq$ & 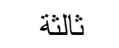 & \\
\hline$v_{.} . r$ & $r 9.90$ & $\leq 7$ & رابعة & \\
\hline 0.94 & $\varepsilon \ldots \leqslant 0$ & $T \varepsilon$. & المجموع & \\
\hline 115.91 & $1 K V .9 \leq$ & $r \cdot \lambda$ & أولى & \multirow{5}{*}{ الاداة ككل } \\
\hline Ir.V. & Irq.Ar & rar & ثانية & \\
\hline 17.11 & $1 Y \wedge .91$ & $9 \leq$ & 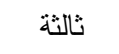 & \\
\hline$|V| \leq$. & ITr.IV & $\leq 7$ & رابعة & \\
\hline $1 \leq .11$ & M.r & $T \leq$. & المجمو ع & \\
\hline
\end{tabular}

جدول رقم (^) المتوسطات الحسابية والاحر افات المعيارية لمعيقات التربية الايمقراطية السياسية والاجتماعية والاقتصادية والتربوية والثقافية والتي تعزى إلى متغير المستوى الاراسي 
Journal of Environmental Studies [JES] 2010. 4: 35- 57

Article

\begin{tabular}{|c|c|c|c|c|c|c|}
\hline الإحصائية & قيمة F & متوسط المربعات & لدرجات & مجموع المربعات & مصادر التباين & المعيقات \\
\hline \multirow{3}{*}{$\ldots \circ$} & \multirow{3}{*}{ E.ror } & Tr.AYo & $r$ & $r_{1} . . \leqslant V T$ & بين المجموعات & \multirow{3}{*}{ السياسية } \\
\hline & & \multirow{2}{*}{10.111} & דידו & 9997.011 & داخل المجموعات & \\
\hline & & & $7 r q$ & $1.197 .99 \varepsilon$ & المجموع & \\
\hline \multirow{3}{*}{$\cdots \cdots$} & \multirow{3}{*}{$11 . r \wedge \varepsilon$} & $r \leq 7 . \wedge \neg \wedge$ & r & $v \leq \cdot .7 \cdot r$ & بين المجموعات & \multirow{3}{*}{ والاجتماعية } \\
\hline & & \multirow{2}{*}{ Y). $7 \wedge 7$} & דזיד & ITVqqY.TY. & داخل المجموعات & \\
\hline & & & rrq & 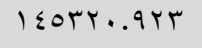 & المجموع & \\
\hline \multirow{3}{*}{$\cdots 17$} & \multirow{3}{*}{ T. $\leq 7 \leq$} & תז. & r & INr.O.. & بين المجموعات & \multirow{3}{*}{ التربوية } \\
\hline & & \multirow{2}{*}{$1 V .07}$. & דיד & $11178.99 \varepsilon$ & داخل المجمو عات & \\
\hline & & & 949 & $1110 . . \leq 9 \leq$ & المجموع & \\
\hline \multirow{3}{*}{ ת4ד. } & \multirow{3}{*}{. .071} & $19.90 r$ & r & 09.100 & بين المجموعات & \multirow{3}{*}{ الثقافية } \\
\hline & & \multirow{2}{*}{ To.ITV } & דזד & TrTE..TE & داخل المجموعات & \\
\hline & & & 749 & $r Y \leq \ldots \leq q \wedge$ & المجموع & \\
\hline \multirow[t]{3}{*}{.$|Y|$} & $1.9 \leqslant V$ & IITr.VVV & צחי & & بين المجموعات & \multirow{3}{*}{ الاداة ككل } \\
\hline & & 1 r $7010 . .$. & r & & داخل المجمو عات & \\
\hline & & IYVVEV.VA & פחד & & المجموع & \\
\hline
\end{tabular}

جدول رقم (9) نتائج اختبار تحليل التباين الأحادي للكثف عن دلالة الفروق بين المتوسطات التي تعزى إلى متغير المستوى الدراسي

\begin{tabular}{|c|c|c|c|c|c|}
\hline رابعة & ثالثة & ثانية & أولى & المستوى الدر اسي & المعيقات \\
\hline. .1197 & $1.7 \wedge 1 r^{*}$ & .r.rr & - & أولى & \multirow{4}{*}{ السياسي } \\
\hline..$- T Y V$ & $1 . \Sigma \vee \wedge q *$ & - & - & ثانبة & \\
\hline$-1.0 \leqslant 17$ & - & - & - & ثالثة & \\
\hline- & - & - & - & رابعة & \\
\hline$-r .0707 *$ & $-Y .0 .9 r^{*}$ & 1.0\% & - & أولى & \multirow{4}{*}{ والاقتصادية } \\
\hline r..TrT & $9 \vee 09$ & - & - & ثانبة & \\
\hline $1.07 \varepsilon$ & - & - & - & ثالثة & \\
\hline- & - & - & - & رابعة & \\
\hline r..V१人* & rVqV & $-\ldots 0 \leq$ & - & اولى & \multirow{4}{*}{ التربوية } \\
\hline$-r . \cdot \vee 9 \Lambda *$ & $-. r V \leq r$ & - & - & ثانية & \\
\hline$-1 . \wedge \ldots r$ & - & - & - & ثالثة & \\
\hline- & - & - & - & رابعة & \\
\hline
\end{tabular}

جدول (· (1) نتائج اختبار شافيه للكثف عن دلالة مصادر الفروق بين المتوسطات التي تعزى الى المستوى الدراسي 
Journal of Environmental Studies [JES] 2010. 4: 35- 57

Article

\begin{tabular}{|c|c|c|c|c|}
\hline الاحمراف المعياري & الوسط الحسابي & العدد & مكان الإقامة & المعيقات \\
\hline 纟.1 & ro.VV & r97 & مدينة & \multirow{5}{*}{ السياسية } \\
\hline$\left\{. Y_{1}\right.$ & rד.人r & سTו & قرية & \\
\hline r.11 & Yт.人т & $9 \vee$ & بادية & \\
\hline r.Ar & rq..V & $11 \leq$ & مخيم & \\
\hline r.99 & Yч.V & $7 \varepsilon$. & المجموع & \\
\hline $0 . r V$ & ro. $\leqslant V$ & r97 & مدينة & \multirow{5}{*}{ الاقتصادية والاجتماعية } \\
\hline$\varepsilon . \leqslant \wedge$ & ro.As & אזו & قرية & \\
\hline r.9v & $r \leqslant . r_{0}$ & $9 \vee$ & بادية & \\
\hline 纟.r. & ro.7s & $11 \leq$ & مخيم & \\
\hline$\varepsilon . V 7$ & ro.si & $7 \varepsilon$. & المجموع & \\
\hline 纟.or & rч.V. & ra7 & مدينة & \multirow{5}{*}{ التربوية } \\
\hline S.YT & Y૫.Аะ & שrו & قرية & \\
\hline$r . \leqslant r$ & rч.r. & qv & بادية & \\
\hline$r .99$ & r.. $9 \mathrm{~V}$ & $11 \leq$ & مخيم & \\
\hline$\{. r)$ & Y૫.VY & $7 \varepsilon$. & المجموع & \\
\hline 7.79 & rq.vq & r97 & مدينة & \multirow{5}{*}{ الثقافية } \\
\hline $0 . Y_{0}$ & ए৭.१ए & שחו & قرية & \\
\hline$\leq .1 \leq$ & $\varepsilon 1.11$ & qv & بادية & \\
\hline $0 . \leqslant \varepsilon$ & $\leq Y .1 \leq$ & $11 \leq$ & مخيم & \\
\hline 0.94 & $\varepsilon \ldots \leqslant 0$ & $7 \leq$. & المجموع & \\
\hline 17.11 & ITV.VE & ra7 & مدينة & \multirow{5}{*}{ الأداة ككل } \\
\hline Ir.V. & $1 \times 9.50$ & אי & قرية & \\
\hline $1 . .00$ & IYA.VI & $9 V$ & بادية & \\
\hline 11.91 & & $11 \leq$ & مخيم & \\
\hline $1 \leq .1 T$ & מצ.r & $7 \varepsilon$. & المجموع & \\
\hline
\end{tabular}

جدول رقم (11) المتوسطات الحسابية والاحمر فات المعيارية لمعيقات التربية الليمقراطية السياسية والاجتماعية والاقتصادية والتربوية و الثقافية والتي تعزى إلى متغير الإقامة.

الإقامة ،كما نلاحظ من الجدول وجود فروق ذات دلالة إحصائية

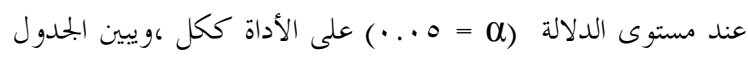

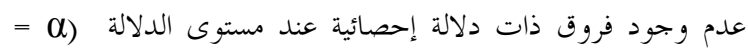

ه ...) في معيقات التربية الديمقراطية الاقتصادية والاجتماعية

والتربوية . وللكشف عن مصادر الفروق على المعيقات السياسية

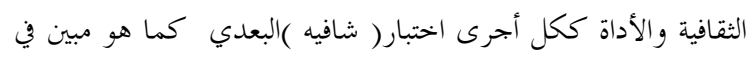

يتبين من الجدول رقم (11) وجود فروق بين المتوسطات الحسابية التي

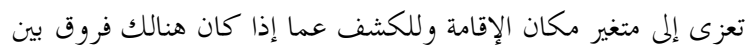
المتوسطات ولفحص دلالة الفروق أجرى تحليل التباين الأحادي كما

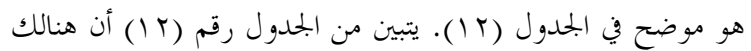

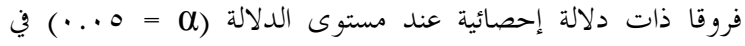

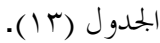
معيقات التربية الديمقراطية السياسية والثقافية التي تعزى إلى متغير 
Journal of Environmental Studies [JES] 2010. 4: 35- 57

Article

\begin{tabular}{|c|c|c|c|c|c|c|}
\hline الاحصلائية & قيمة F & متوسط المربعات & درجات الحرية & مجموع المربعات & مصادر التباين & المعيقات \\
\hline \multirow{3}{*}{$\cdots \cdots$} & \multirow{3}{*}{$r \cdot . \leqslant V_{0}$} & ห99.rדV & $r$ & $199.1 \cdot r$ & بين المجموعات & \multirow{3}{*}{ السياسي } \\
\hline & & \multirow{2}{*}{$|\leq .74|$} & דידי & 9Y9人.^9r & داخل المجموعات & \\
\hline & & & 947 & $1.197 .99 \varepsilon$ & المجموع & \\
\hline \multirow{3}{*}{$\cdots 1 \ldots$} & \multirow{3}{*}{$r . . \wedge q$} & EV.TV. & $r$ & $1 \leq 1 . \wedge 1$. & بين المجموعات & \multirow{3}{*}{ والاقتصادي } \\
\hline & & \multirow{2}{*}{ TY.TYA } & דוד & $1 \leq 491.114$ & داخل المجموعات & \\
\hline & & & 9 & IEOTr.9YT & المجموع & \\
\hline \multirow{3}{*}{.790} & \multirow{3}{*}{$\cdot . \leqslant \wedge r$} & $1.0 \vee 9$ & $r$ & ro.VTA & بين المجموعات & \multirow{3}{*}{ التربوي } \\
\hline & & \multirow{2}{*}{$1 V . \Lambda .7$} & דיד & MTYE.VOT & داخل المجموعات & \\
\hline & & & 749 & $1110 . .59 \varepsilon$ & المجموع & \\
\hline \multirow{3}{*}{$\cdots \cdots$} & \multirow{3}{*}{$0 . r \leq 9$} & $|A . . \leq Y|$ & $r$ & $0 \leq 1.179$ & بين المجموعات & \multirow{3}{*}{ الثقافي } \\
\hline & & \multirow{2}{*}{$r \varepsilon . r v}$. & דיד & r)109.rTE & داخل المجموعات & \\
\hline & & & 749 & $r r \leq \ldots . \varepsilon 9 \wedge$ & المجموع & \\
\hline \multirow{3}{*}{$\cdots \cdots$} & \multirow{3}{*}{$0 . r \leq 0$} & $1 . r \wedge .117$ & $r$ & $r \cdot \wedge \leq . r \leq V$ & بين المجموعات & \multirow{3}{*}{ الاداة ككل } \\
\hline & & \multirow{2}{*}{$179 . .15$} & דזד & Ir $\leq 7 \pi T . \leq r$ & داخل المجموعات & \\
\hline & & & 949 & IYVVEV.VV & المجموع & \\
\hline
\end{tabular}

جدول (r (1) نتائج اختبار تحليل التباين الأحادي للكثُف عن دلالة الفروق بين المتوسطات التي تعزى إلى متغير الإقامة

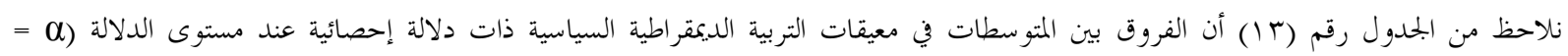

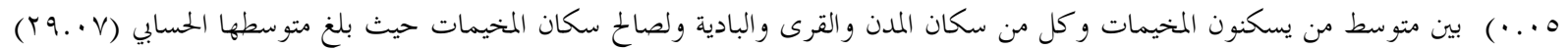

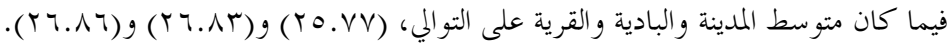

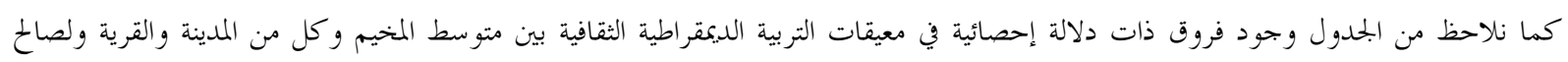

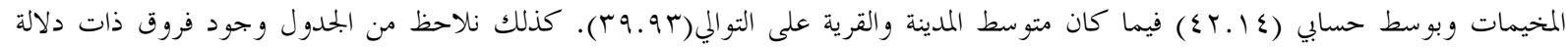

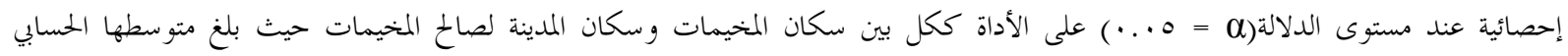

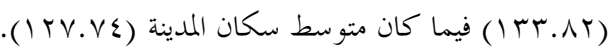

رابعا: العضوية

هل توجد فروق ذات دلالة إحصائية عند مستوى الدلالة (a = ـ0 ·) في معيقات التربية الديمقراطية كما يتصورها طلبة الجامعات الأردنية تعزى إلى

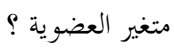

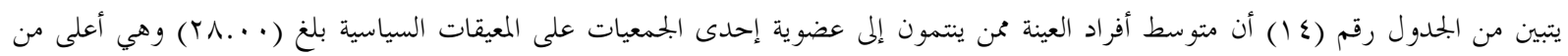

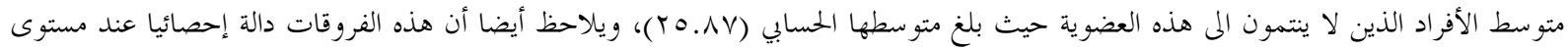

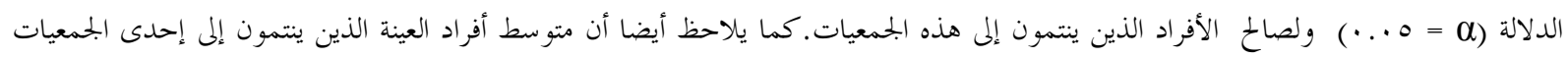

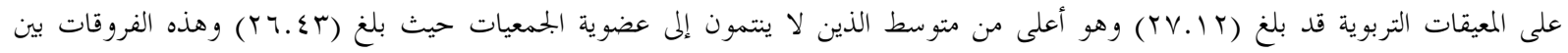

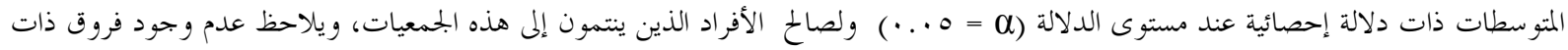
دلالة إحصائية عند مستوى الدلالة (م = ه ... ) على المعيقات (الاجتماعية والاقتصادية والثقافية ). 
Journal of Environmental Studies [JES] 2010. 4: 35- 57

Article

\begin{tabular}{|c|c|c|c|c|}
\hline مخيم & بادية & قرية & الإقامة & المعيقات \\
\hline -r.Y970* & $-1 . .9 r r$ & $-1 . \cdot 7 \cdot 9$ & مدينة & \multirow{4}{*}{ السياسي } \\
\hline -r.YrOY* & $-. . \cdot \mu_{1} \leq$ & - & قرية & \\
\hline$-Y . Y \cdot \Sigma r^{*}$ & - & - & بادية & \\
\hline- & - & - & مخيم & \\
\hline$-. .17 \vee \leq$ & I.IKro & -. TVTV & مدينة & \multirow{4}{*}{ والاجتماعية } \\
\hline .r.qr & $1 .\{991$ & - & قرية & \\
\hline$-1 . r \wedge 9 \wedge$ & - & - & بادية & \\
\hline- & - & - & مخيم & \\
\hline דצY & . & . . . & مدينة & \multirow{4}{*}{ التربوية } \\
\hline.$- .1 \% 17$ & . . OrkA & - & قرية & \\
\hline$-. .77 \leq \varepsilon$ & - & - & بادية & \\
\hline- & - & - & مخيم & \\
\hline$-r . r \leq \neg \leq *$ & 1.4917 & $-.1 T \wedge \varepsilon$ & مدينة & \multirow{4}{*}{ الثقافية } \\
\hline$-Y \cdot r \cdot \Lambda \cdot * *$ & I.rorr & - & قرية & \\
\hline $.90 \leqslant 1$ & - & - & بادية & \\
\hline- & - & - & مخيم & \\
\hline$-7 . . \vee \vee \vee 9 *$ & $-. .97 \leq V$ & $-1 . V I r$. & مدينة & \multirow{4}{*}{ الأداة ككل } \\
\hline$-\varepsilon .4709$ & $\cdot . V \leqslant V T$ & - & قرية & \\
\hline Kr & - & - & بادية & \\
\hline- & - & - & مخيم & \\
\hline
\end{tabular}

جدول (r ( ) نتائج اختبار شافيه للكثف عن دلالة مصادر الفروق بين المتوسطات التي تعزى الى مكان الإقامة

\begin{tabular}{|c|c|c|c|c|c|c|}
\hline مستوى الدلالة & درجات الحرية & قيمة & الآحر اف & المتوسط & العضوية & المعيقات \\
\hline \multirow{2}{*}{$\cdots \cdots$} & \multirow{2}{*}{ Th } & \multirow{2}{*}{$-7 . \wedge \varepsilon}$. & r.9r & ro.AV & y & \multirow{2}{*}{ السياسية } \\
\hline & & & $r . V T$ & ґ^... & نعم & \\
\hline \multirow{2}{*}{.79} & \multirow{2}{*}{ 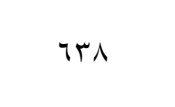 } & \multirow{2}{*}{..$\% 99$} & $\{.91$ & ro.sV & y & \multirow{2}{*}{ الاقتصادية و الاجتماعية } \\
\hline & & & $\varepsilon .00$ & rur & ن نعم & \\
\hline \multirow{2}{*}{$\cdots \leqslant 1$} & \multirow{2}{*}{ 落 } & \multirow{2}{*}{$-r_{.} \cdot \leq r$} & $\varepsilon . . r$ & rצ. & y & \multirow{2}{*}{ التربوية } \\
\hline & & & $\varepsilon . \leqslant 0$ & tr.itr & نعم & \\
\hline \multirow{2}{*}{ •.人Tו } & \multirow{2}{*}{ Tr } & \multirow{2}{*}{$-\cdot r \mid r$} & $7 . . r$ & $\leq . . \leqslant 1$ & y & \multirow{2}{*}{ الثقافية } \\
\hline & & & $0 . V 7$ & $\{. .01$ & نعم & \\
\hline \multirow{2}{*}{$\cdots 10$} & \multirow{2}{*}{ т人 } & \multirow{2}{*}{$-r . \leqslant Y \wedge$} & $|\leq . r|$ & IrA.r. & y & \multirow{2}{*}{ الأداة ككل } \\
\hline & & & Tr.v & 11.997 & نعم & \\
\hline
\end{tabular}

جدول (؛ ( ) نتائج فحص الفروق في معيقات التربية الايمقر اطية التي تعزى إلى متغير العضوية (T- test) 
معلنة ومنظمة داخلها مما انعكس ايجابياً على المستوى السياسي

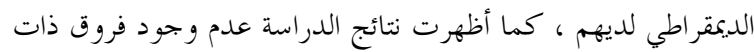

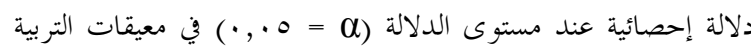
الديمقراطية الاجتماعية والاقتصادية ، و التربوية والتي ت تعزى إلى متغير لهيه

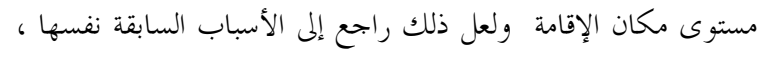
والى حالة التوافق في حياهم بحثا عن الانسجام بين حياهم الطلابية

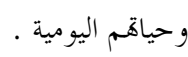

وأظهرت نتائج الدراسة وجود فروق ذات دلالة إحصائية عند

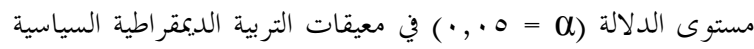
، والتربوية و والتي تعزى إلى متغير المستوى العضوية لصالح الأفراد

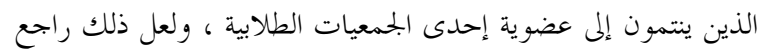
الى وعي الطلبة الذين ينتمون الى الجمعيات الطلابية بمعيقات التربية

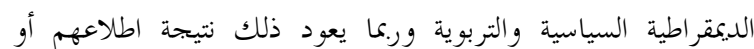
منعهم من ممارسة تلك المعيقات داخل الجامعات . . كما أظهرت نتائج

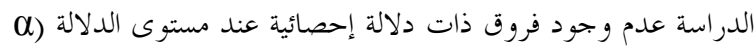

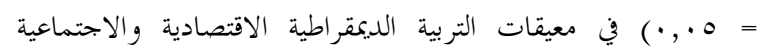

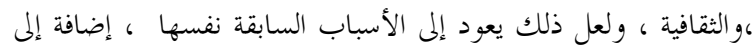
أن الطلبة متفقون على هذه المعيقات بشكل متساو.

\section{التوصيات}

إعطاء الطلبة مزيدا من الديمقراطية الحقيقية .ما يسمح لهم

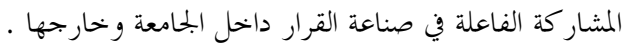
تبني استراتيجيات لتطوير المناهج في الجامعات وإيجاد مساقات تتعلق بالتربية الديمقراطية .

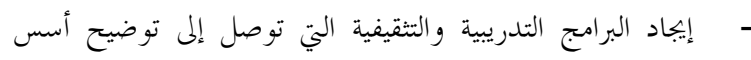
ومبادئ الديمقراطية . .

تنشيط العمل الجماعي والتطوعي في المؤسسات الوطنية ومن خلال الاتحادات والجمعيات الطلابية . نشر الثقافة الديمقراطية في جميع بجالات الحياة للتغلب على سلبيات العمل الديمقراطي .

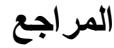

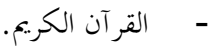
-

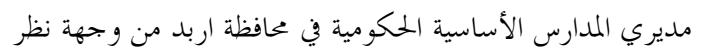

كما يلاحظ أيضا وجود فروق ذات دلالة إحصائية عند مستوى

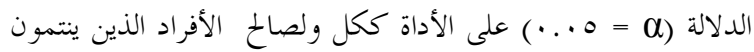
إلى عضوية إحدى الجمعيات الطلابية.

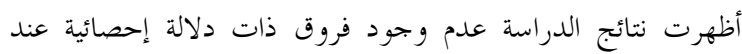

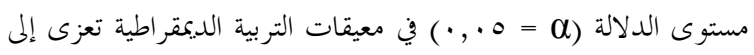
متغير الجنس وقد يعزى ذلك إلى أن معيقات التربية الديمقراطية عند

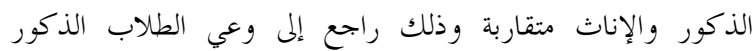
والطالبات الإناث .معيقات التربية الديمقراطية وعيا ناتجا عن البيئة التعليمية في المدرسة أو في الجامعة التي يعيش فيها الطلبة تلك البيئة التي لا تختلف كثيرا عن بعضها البعض من جهة ولا تختلف عن المن البيئة البختمعية والأسرية بشكل عام إذ إن اهتمام الجهات الرسمية في التربية

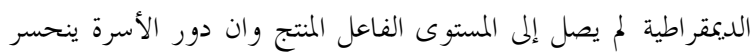
تدريجا كلما تقدم الطالب ذكر كان أم أنثى في المستوى الدراسي . كما أظهرت نتائج الدراسة وجود فروق ذات دلالة إحصائية

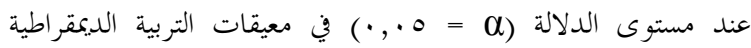

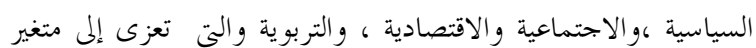
المستوى الدراسي ، وقد يعزى ذلك إلى اختلاف المساقات التدريسية

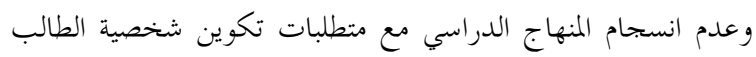

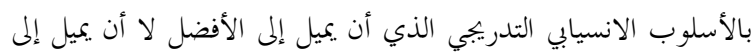
الموقف الذي يو اجه الطالب في كل سنة دراسية .

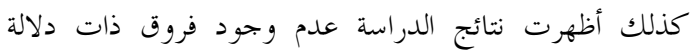

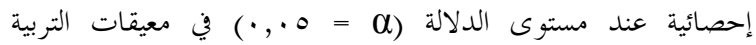
الديمقراطية الثقافية في المستوى الدراسي ، وذلك لميل الطلبة التحصيلي

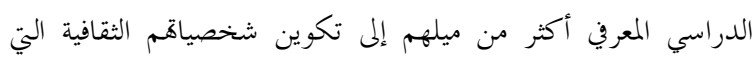

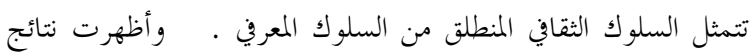
الدراسة وجود فروق ذات دلالة إحصائية عند مستوى الدلالة (م)

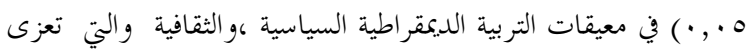
إلى متغير مستوى مكان الإقامة ولعل ذلك راجع إلى تغير البيئة التي

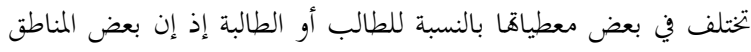

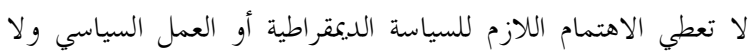
الثقافة أو العمل الثقافي وهذا يولد حالة فراغ لدى الطالب أو الطالبة

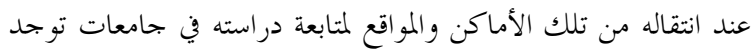

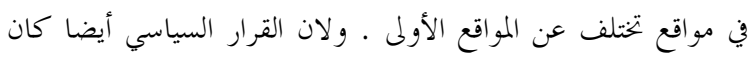
يميل إلى دعم أبناء المخيمات البيئة الصالحة لتثقيفهم سياسيا وثقافيا منا

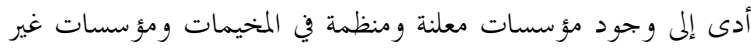


الصرايره علي جميل، معوقات التنمية السياسية في الأردن، دراسة

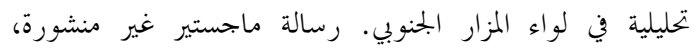

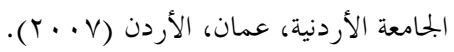

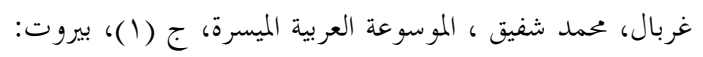
دار فضة لبنان للطبع والنشر( • (199).

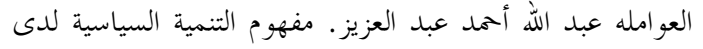
طلبة كليات العلوم التربوية في الجامعات الأردنية. رسالة دكتوراه غير منشورة، الجامعة الأردنية، عمان، الأردن (0. . . ب). إهام فرج ، برنامج سلوكي مقترح لتنمية السلوك الديمقراطي والتفاعل الاجتماعية للمعلم العربي. ضمن مركز لمرت دراسات الوحدة، الديمقراطية والتربية في الوطن العربي: أعمال المؤتمر

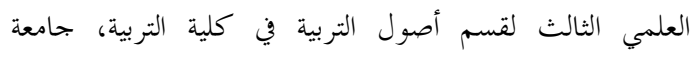

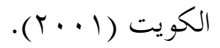

كيلاني شادية ، واقع البرلمان المدرسي ودورة في تربية الديمقراطية

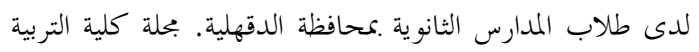

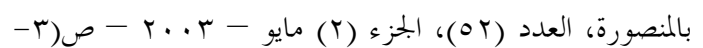
$\cdot(r \cdot r)(T)$

وزارة التعليم العالي والبحث العلمي،إحصائية الطلبة الملتحقين

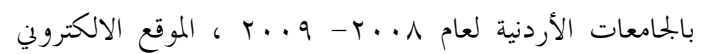

. Www.mohe.gov.jo.

وطفة علي أسعد، الديمقراطية التربوية من ديمقراطية المدرسة إلى

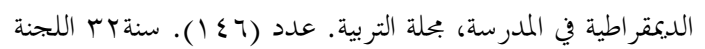
الوطنية القطرية للتربية والثقافة والعلوم(ب . . r).

- Alfano, M. 2001. "Pre-service teachers perceptions toward the meaning and purpose of democratic in urban, schools: A case study". (ERIC, DAI-A 62/09, P.3016. Mar 2002.

- Gillespie L. 1996. "Classrooms as Democratic Communication" Paper presented at the summer workshop of the Association of Teacher Education", Albama, USA, August 3-7, (Eric, ED 401246).

- Joseph, M. 2000. "Democratic education: Building tomorrow's citizens in Today's

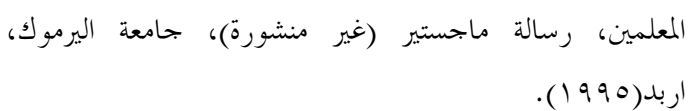

التل سعيد ، وتوفيق مرعي، احمد ابو هلال، و انمار الكيلاني،

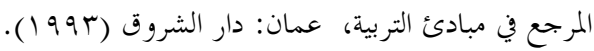

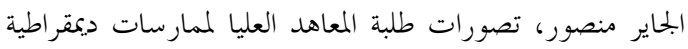
التعليم في ليبيا، رسالة ماجستير غير منشورة. جامعة اليرموك.

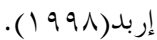
حمادة عبد المحسن ،و محمد الصاوي ، إسهام النظام التعليمي في إصلاح المسيرة الديمقراطية في الكويت، دراسة ميدانية، ضمن مركز دراسات الوحدة العربية، الديمقراطية والتربية في الوطن العربي، أعمال المؤتمر العلمي الثالث لقسم أصول التربية في كلية

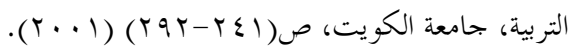

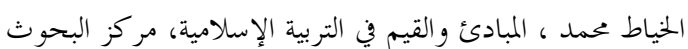
التربوية والنفسية، مكة المكرمة (79 99 (1).

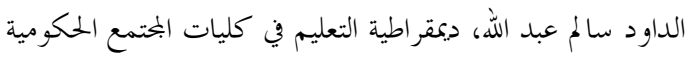

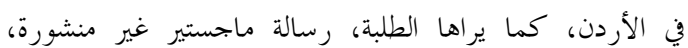
الجامعة الأردنية، عمان(ع (199 1) ).

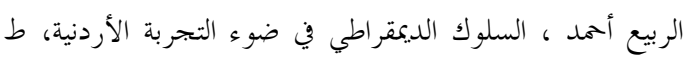
(1)، عمان: المكتبة الوطنية (1999 (1).

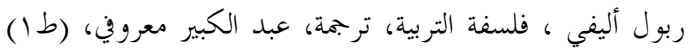
المغرب: دار توبقال للنشر(ع 99 (1). الرشدان عبد الكريم أحمد ، دراسة تحليلية للمبادئ والقيم الديمقراطية في فلسفة التربية والتعليم في الأردن، رسالة دكتوراه

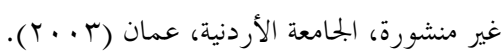
الرفوع فيصل، التنمية السياسية بين النظرية والتطبيق : الأردن الإدهن

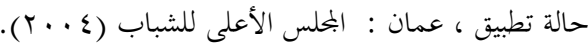

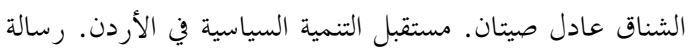
ماجستير غير منشورة، كلية الدفاع الوطني الملكية الأردنية،

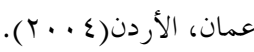
الشيباني عمر ، "مفهوم ومبادئ وأهداف التنمية السياسية العربية"

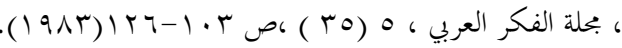

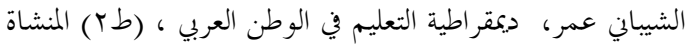
العامة للنشر والتوزيع والإعلان ليبيا: طرابلس (7 9 (1) ). الصاوي محمد وجيه. دراسات في الفكر التربوي الإسلامي، لإسيا. الكويت، مكتبة الفلاح (1999 1). 
Article

- Michael A. and O'Malley R. 2003. "Democracy and Education: Liberty \& Justice for A11? Journal articles, P38-40.

- Weakly J. 1994. Voices from room 23. Journal articles (ERIC EJ4869551)
Classrooms". (ERIC, MAI 39/02, p.336, Apr. 2001).

- Mendel R. and Meta W. 1996. "Community Service Learning as Democratic Education in South Africa and the United States. Michigan Journal of Community Service Learning, (ERIC EJ552449).

\title{
Education and its relationship with some demographic variables as detected with a sample of Jordanian university students
}

\author{
${ }^{1}$ Abdullah A. Al Awamleh, ${ }^{2}$ Jamal F. Al Omari and ${ }^{3}$ Saleh S. Barkat \\ ${ }^{1,2,3}$ Assistant professor Al balqa Applied University
}

\begin{abstract}
This study aims to know the obstacles of the democratic, political, social, economic, educational, and cultural education from the university of Jordan students' point of view and to know the effect of study variances such as gender, the academic level, place of living and the student's membership in students' clubs. The researchers developed the study instrument this study aims to answer the following questions:

1- What are the democratic, political, social, economic, educational, cultural obstacles from the university of Jordan students' view?

2- Are there any statistically significant differences at level $0.05=\mathrm{a}$ in the democratic education obstacles due to sex, academic level, place of living, and students' membership

The study sample consists of 640 students who study in public universities 344 male student and 296 female students. This study shows that there are obstacles in all fields of study and mostly in cultural obstacles. Also, it shows that there were no statistical differences at level $0.05=\mathrm{a}$ in sex variance for males and females, but there were statistical differences at level $0.05=\mathrm{a}$ in the democratic political, social education, obstacles and for students' membership. Also, there were no statistical differences at level .05 due to place of living in all economic , social and educational obstacles, where as it was statistical at level .05 democratic, political and cultural education lastly. This study shows that there are statistical sign cant differences level .05 in the democratic educational due to student's member ship for students who attend students committees.
\end{abstract}

Key words: democratic, education, obstacles, university students. 